UNIVERSITÄTSBIBLIOTHEK BRAUNSCHWEIG

Jens Bange, Peter Zittel, Thomas Spieß, Jörg Uhlenbrock and Frank Beyrich

\title{
A New Method for the Determination of Area-A veraged Turbulent Surface Fluxes from Low -Level Flights Using Inverse Models
}

URL: http://ww w .digibib.tu-bs.de/? docid $=00015757$

Zuerst erschienen in:

Boundary-Layer M eteorology, Springer Netherlands, 119(2006), Nr. 3, S. 527-561

The original publication is available at www.springerlink.com.

DOI: $10.1007 /$ s10546-005-9040-6

http://springerlink.metapress.com/content/2334h2p8182154n4/fulltext.pdf

HINWEIS:

Dieser elektronische Text wird hier nicht in der offiziellen Form

wiedergegeben, in der er in der Originalversion erschienen ist. Es gibt keine inhaltlichen Unterschiede zwischen den beiden Erscheinungsformen des Aufsatzes ; es kann aber Unterschiede in den Zeilen- und Seitenumbrüchen geben. 


\title{
A NEW METHOD FOR THE DETERMINATION \\ OF AREA-AVERAGED TURBULENT SURFACE FLUXES FROM LOW-LEVEL FLIGHTS USING INVERSE MODELS
}

\author{
JENS BANGE ${ }^{1, *}$, PETER ZITTEL ${ }^{1}$, THOMAS SPIEß ${ }^{1}$, \\ JÖRG UHLENBROCK ${ }^{2}$ and FRANK BEYRICH ${ }^{3}$ \\ ${ }^{1}$ Institute of Aerospace Systems, Technical University of Braunschweig, Braunschweig, \\ Germany; ${ }^{2}$ Institute for Meteorology and Climatology, University of Hannover, Hannover, \\ Germany; ${ }^{3}$ Meteorological Observatory Lindenberg, German Meteorological Service (DWD), \\ Lindenberg, Germany
}

(Received in final form 22 November 2005)

\begin{abstract}
The low-level flight method (LLF) has been combined with linear inverse models (IM) resulting in an LLF+IM method for the determination of area-averaged turbulent surface fluxes. With this combination, the vertical divergences of the turbulent latent and sensible heat fluxes were calculated from horizontal flights. The statistical errors of the derived turbulent surface fluxes were significantly reduced. The LLF+IM method was tested both in numerical and field experiments. Large-eddy simulations (LES) were performed to compare 'true' flux profiles with 'measurements' of simulated flights in an idealised convective boundary layer. Small differences between the 'true' and the 'measured' fluxes were found, but the vertical flux divergences were correctly calculated by the LLF+IM method. The LLF+IM method was then applied to data collected during two flights with the Helipod, a turbulence probe carried by a helicopter, and with the research aircraft Do 128 in the LITFASS-98 field campaign. The derived surface fluxes were compared with results from eddy-covariance surface stations and with large-aperture scintillometer data. The comparison showed that the LLF+IM method worked well for the sensible heat flux at 77 and $200 \mathrm{~m}$ flight levels, and also for the latent heat flux at the lowest level. The model quality control indicated failures for the latent heat flux at the $200 \mathrm{~m}$ level (and higher), which were probably due to large moisture fluctuations that could not be modelled using linear assumptions. Finally the LLF+IM method was applied to more than twenty low-level flights from the LITFASS-2003 experiment. Comparison with aggregated surface flux data revealed good agreement for the sensible heat flux but larger discrepancies and a higher statistical uncertainty for the latent heat flux.
\end{abstract}

Keywords: Airborne measurements, Area-averaged turbulent fluxes, Heterogeneous surface, Inverse models, LITFASS, Statistical errors.

\section{Introduction}

The determination of the area-averaged turbulent fluxes at the earth's surface during a field experiment is desirable for several reasons e.g.,

* E-mail: j.bange@tu-bs.de 
the closure of the energy balance or the initialisation or validation of numerical atmospheric models. Long-term measurements are preferably done with ground-based installations, and it should be kept in mind that micrometeorological ground-stations, towers, and remote sensing systems like wind profilers, sodar, or lidar provide point measurements. Even with the application of Taylor's hypothesis (Taylor, 1938; Powell and Eldekin, 1974; Browne et al., 1983) ground-based measurements cannot represent a whole area (e.g., Mahrt and Ek, 1993; Isaac et al., 2004). This is especially true in a heterogeneous terrain where the measurement results depend on the 'fetch' - the footprint of the area upstream - i.e., the wind direction and velocity, the surface type and roughness, elevation, time of day, radiation, etc. (e.g., Haenel and Grünhage, 1999; Mahrt et al., 2001; Beyrich et al., 2002a).

An averaging method is necessary that allows calculation of an area-representative turbulent flux from ground-based spot measurements. The definition of a suitable strategy was the scientific subject in two recent research programs: EVA-GRIPS (Regional Evaporation at Grid/Pixel Scale over Heterogeneous Land Surfaces) and VERTIKO (vertical transport of energy and trace gases at anchor stations under complex natural conditions).

To obtain a 'truth' for validation of the averaging strategies it is necessary to have at least one system involved that measures the actual area-representative turbulent fluxes. An ideal observation of the area-averaged fluxes means averaging over the time and all points of the regarding area (Grossman, 1992b), requirements that could be fulfilled by satellites. Unfortunately satellite data must still be validated by ground data, require cloudless skies, and are not that reliable regarding turbulent transport. Nevertheless first attempts in calculating surface sensible and latent heat fluxes exist via the application of simple (climatological) assumptions (Berger, 2002).

So, at present, the best solution involves in situ airborne measurements. Aircraft cover, for instance, a $20 \mathrm{~km} \times 20 \mathrm{~km}$ area within tens of minutes, depending on the flight strategy and aircraft speed. During this time the non-stationarity of the atmospheric boundary layer (ABL) can be estimated by simple (possibly linear) assumptions about the ABL development. Aircraft fly at least one order of magnitude faster than the typical ABL wind, and Taylor's hypothesis of frozen turbulence is therefore widely fulfilled on flight legs (straight and level flight sections) of a few kilometres length. A simple comparison demonstrates the advantage of airborne measurements concerning mean turbulent fluxes: to observe at least a few large convection elements on a sunny afternoon over land an averaging distance of $20 \mathrm{~km}$ or more is required. A typical research aircraft needs clearly less than $10 \mathrm{~min}$ to fly this $20 \mathrm{~km} \mathrm{leg}$. For a tower (at a proper position downstream) it takes 
more than $1 \mathrm{~h}$ to manage the same fetch for an ABL wind speed of $5 \mathrm{~m} \mathrm{~s}^{-1}$ (e.g., Angevine et al., 1993).

The systematic measurement errors of research aircraft have been discussed at length during the last 15 years (Desjardins et al., 1989; Betts et al., 1992; Kelly et al., 1992; Mann and Lenschow, 1994; Jacobi et al., 1995; Busch et al., 1996; Heinemann, 2002). Sensor and data sampling techniques for the measurement of the ABL dynamics (i.e., wind, temperature, humidity) have improved a lot during the last years. Nevertheless systematic sensor errors may occur especially on new systems but are quickly identified in comparison experiments (i.e., Lambert and Durand, 1998; Isaac et al., 2004). The systems introduced here - the Helipod and the Do 128, both of the Technical University of Braunschweig - are wellproven research instruments that demonstrated the quality of their measured data in several field experiments.

The statistical uncertainty of airborne turbulence measurements (and all other turbulence observations) is mainly a matter of the measurement strategy. It has been made clear that 'the longer - the better' (Lenschow and Stankov, 1986; Lenschow et al., 1994) is an easy rule to follow when observing the convective ABL (CBL). Unfortunately it is always necessary to make a compromise between the averaging length and the experimental set-up (size of the area of interest, non-stationarity of the CBL, aircraft speed). The flight strategies (flight patterns) presented here are of such a compromise. With sophisticated sensor and data sampling techniques and a suitable flight strategy, area-averaged turbulent fluxes can be measured with acceptable statistical uncertainty at the flight level.

A common method to determine the area-representative surface fluxes from airborne measurements at two or more levels is through extrapolation to the ground. This procedure (named the box method in the following) assumes a certain (usually linear) shape of the flux profile across a large portion of the ABL. It has been often applied to estimate the surface sensible heat flux in a CBL (e.g., Betts et al., 1990; Grunwald et al., 1996; Durand et al., 1998). The method is simple, but in comparison with simultaneous ground-based measurements often systematic discrepancies have been observed.

Another technique for the estimation of area-averaged surface fluxes is the $\mathrm{ABL}$ budget method, which uses the integrated budget equations of heat, water vapour or carbon dioxide in the CBL (e.g., de Arellano et al., 2004). This determines the mean surface fluxes from the evolution of the ABL height and from the changes of mean state variables inside the CBL. Budget methods rely on a number of assumptions that limit their applicability, both advection and the synoptic-scale vertical velocity must be known or negligible: the ABL is assumed to be well mixed so that mean state variables can be determined with small uncertainties, and the 
entrainment flux is usually parameterised as a fixed fraction of the surface flux. Budget methods are often quite sensitive to measurement errors and uncertainties. Apart from these restrictions, budget methods have been successfully applied for the estimation of area-averaged fluxes in a number of studies (e.g., Betts et al., 1992; Denmead et al., 1996; Gryning and Batchvarova, 1999) and yield good results even in non-ideal situations (Beyrich et al., 2002a; Cleugh et al., 2004). Best results were obtained for larger averaging times up to daily values, while short-term $(2 \mathrm{~h})$ results showed larger differences to ground-based measurements or were physically implausible.

The present study introduces a comparatively simple and scarcely limited method for the determination of the area-averaged turbulent surface fluxes from single low-level flights. The flight strategy was combined with an inverse model, and the new method was named LLF+IM (low-level flights with inverse modelling). The new method was verified via large-eddy simulation (LES) and comparable measurements of two airborne systems and ground-based measurements during the LITFASS-98 field experiment. Finally the LLF+IM method was applied to airborne measurements during the LITFASS-2003 experiment.

\section{Flight Strategies}

\subsection{Box FLIGHTS}

For the determination of the mean turbulent surface fluxes in a CBL the usual method is to fly area-covering flight patterns e.g. four legs of 10-20 km length each, forming a square for more complicated squareshaped patterns (see Scherf and Roth, 1997 or Grunwald et al., 1996). The flights have to be repeated at at least two different altitudes within the $\mathrm{CBL}$; this strategy is named the box method in the following. At each flight level $z_{f}$ the area-averaged flux (in this example the vertical flux of sensible heat) is determined by

$$
H_{z_{f}}=\rho\left(z_{f}\right) c_{p} \frac{1}{n} \sum_{i=1}^{n}\left\langle w^{\prime} \theta^{\prime}\right\rangle_{i},
$$

where $\rho$ is the air density and $c_{p}$ the specific heat at constant pressure. The turbulent fluctuations $w^{\prime}$ and $\theta^{\prime}$ of the vertical wind and the potential temperature, respectively, are averaged $(\langle\ldots\rangle)$ only over straight and level flight sections. Applying the simple box flight pattern, the number of legs $n=4$. Assuming a linear heat flux profile in the CBL the area-averaged fluxes are then extrapolated to the ground (e.g., Durand et al., 1998). 
The drawbacks of this method are obvious: firstly, a linear flux profile through the entire ABL has to be assumed. This is not problematic for the sensible heat fluxes in a CBL, but unlikely for momentum and latent heat near the surface and for other types of thermal stratification (e.g. Deardorff, 1974). Secondly, flights at a minimum of two different altitudes are necessary (or three to obtain a minimum of certainty that the flux profile is indeed linear), which is costly. And thirdly, for the duration of the flights stationarity or at least a linear temporal development of the CBL has to be assumed.

The latter is considered by applying a scaling of the altitude using the height $z_{i}$ of the capping inversion of the CBL (e.g. Grant, 1986). For a complete scaling (Deardorff, 1970) the kinematic flux $\left\langle w^{\prime} \theta^{\prime}\right\rangle$ at flight level $z_{f}$ has to be divided by the surface kinematic flux $\left\langle w^{\prime} \theta^{\prime}\right\rangle_{0}$ measured during the same period. This is, of course, not possible since the surface flux is the quantity to be sought from the experiment.

Figure 1 shows the results of a devised flight experiment. In a CBL the heat flux profile below the capping inversion can be approximated by a linear function of height $z$. Let us assume that the heat flux and the height of the CBL are increasing in time, as in a developing CBL before the radiation maximum is reached. The upper diagram demonstrates the situation for three successive airborne flux measurements at times $t_{1}, t_{2}$, and $t_{3}$. In this situation (increasing flux and aircraft runs at increasing altitudes) a simple linear extrapolation of the airborne measurements would clearly underestimate the surface heat flux. Such systematic discrepancies between extrapolated fluxes and ground-based measurements were reported several times (Betts et al., 1990, 1992; Grunwald et al., 1996; Durand et al., 1998), and an overview was given by Isaac et al. (2004). Systematic measurement errors (e.g. due to short flight legs or filters) were mostly excluded as an explanation for the differences.

After Deardorff scaling (centre diagram) the three profiles are joined and the airborne measurements are perfectly located on that line. Since the surface kinematic flux $\left\langle w^{\prime} \theta^{\prime}\right\rangle_{0}$ is not known in real flight experiments, this scaling is in practice not possible. But scaling only the height axis (bottom diagram in Figure 1) leads also to a systematic underestimation of the turbulent surface fluxes.

\subsection{LOW-LEVEL FLIGHTS}

Grunwald et al. (1998) introduced the low-level flight method (LLF) to determine the surface fluxes using flights at only one low altitude. In desert regions such flights can be performed very low so that the measured fluxes can directly be interpreted as surface values with only a small error (Isaac et al., 2004). But, in general, flight measurements over land, especially in 
J. BANGE ET AL.
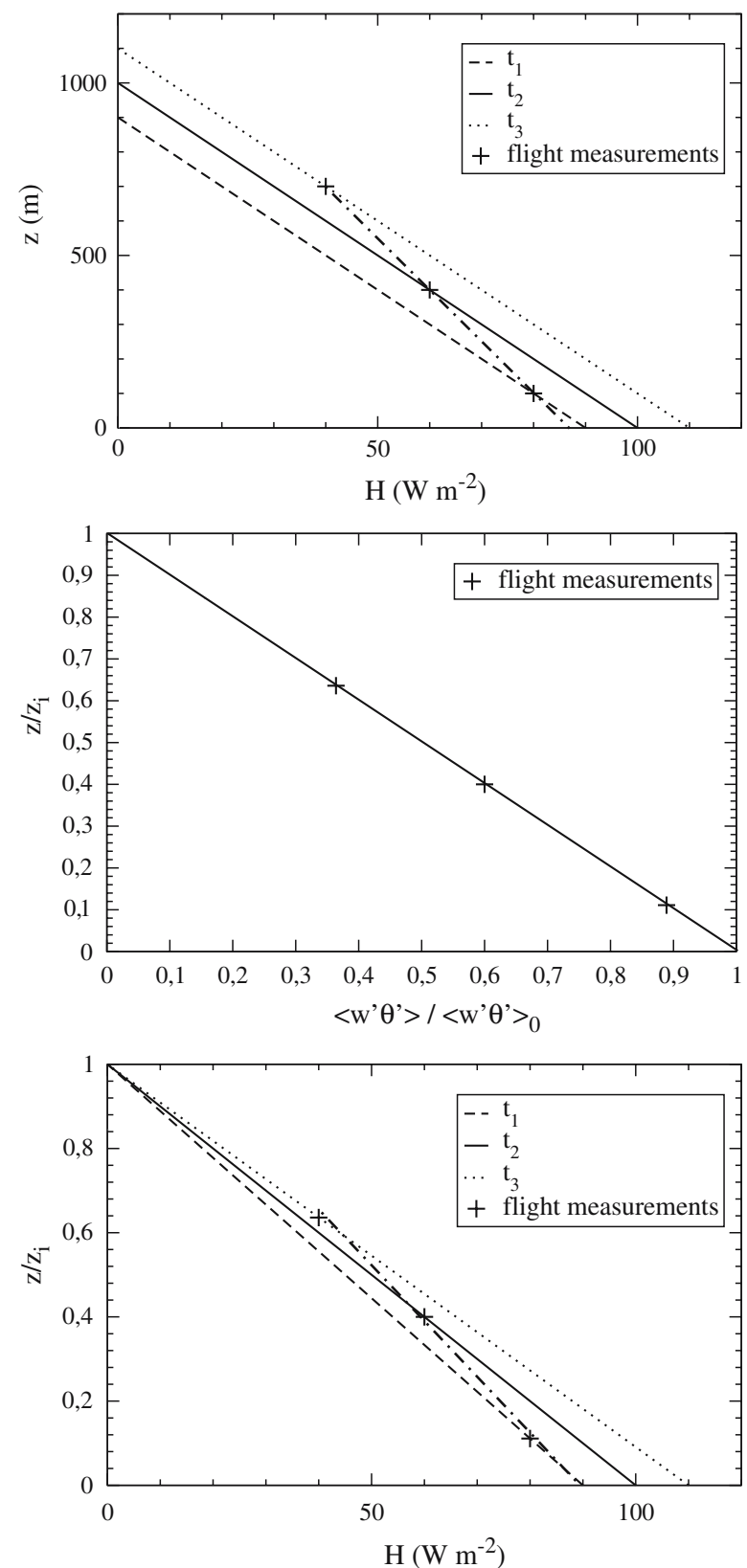

Figure 1. Heat flux profile of a devised flight experiment. The solid, dashed, and dotted lines represent the heat flux profiles of the CBL at three different times. The cross marks indicate three successive airborne flux measurements. The short dashed-dotted lines represent the linear extrapolation of these measurements to the ground. Top diagram: no scaling. A linear extrapolation of the flight measurements would underestimate the surface flux. Centre diagram: Deardorff scaling. Bottom diagram: only altitude scaling. Also here a linear extrapolation of the measurements would underestimate the surface flux. 
populated regions, cannot be performed low enough that an extrapolation to the ground would be unnecessary. Vertical flux divergence is significant even at flight levels between 10 and $50 \mathrm{~m}$ (Desjardins et al., 1989).

From the first fundamental theorem of thermodynamics follows the continuity equation for sensible heat

$$
\frac{\partial \bar{\theta}}{\partial t}+\nabla\langle\theta \vec{v}\rangle=0
$$

with wind vector $\vec{v}=(u, v, w)$ and mean potential temperature $\bar{\theta}$. The divergence or vertical gradient of the sensible heat flux $H$ can be determined via Reynolds decomposition (in a divergence-free flow):

$$
-\frac{1}{\rho c_{p}} \frac{\partial H}{\partial z}=\frac{\partial \bar{\theta}}{\partial t}+\langle(\bar{u}, \bar{v}, \bar{w})\rangle \operatorname{grad} \bar{\theta}+\frac{\partial\left\langle u^{\prime} \theta^{\prime}\right\rangle}{\partial x}+\frac{\partial\left\langle v^{\prime} \theta^{\prime}\right\rangle}{\partial y},
$$

where the mean vertical wind $\bar{w}$ is assumed to be close to zero. The horizontal divergence of the turbulent flux can also be disregarded since it is assumed to be small compared to the remaining terms:

$$
\frac{\partial\left\langle u^{\prime} \theta^{\prime}\right\rangle}{\partial x}+\frac{\partial\left\langle v^{\prime} \theta^{\prime}\right\rangle}{\partial y} \approx 0 .
$$

Thus (3) can be reduced to (see also Betts et al., 1990; Grossman, 1992a; Scherf and Roth, 1997)

$$
\frac{1}{\rho c_{p}} \frac{\partial H}{\partial z}=-\frac{\partial \bar{\theta}}{\partial t}-\left(\bar{u} \frac{\partial \bar{\theta}}{\partial x}+\bar{v} \frac{\partial \bar{\theta}}{\partial y}\right) .
$$

The vertical gradient of the latent heat flux $\lambda E$ can be deduced in a similar way.

To obtain the surface flux, assumptions about the vertical profiles of the fluxes between the surface and the flight level have to be made. Since the flights should be performed as low as possible this is necessary only for the lowest part of the ABL, typically not more than the lowest $100 \mathrm{~m}$. In our example - the turbulent heat flux in the CBL - the surface heat flux is determined using simple linear extrapolation:

$$
H_{0}=H_{z_{f}}-\left(\frac{\partial H}{\partial z}\right) z_{f} .
$$

However, there are more sophisticated methods available (Burns et al., 1999).

The LLF strategy consumes less flight time and has therefore big advantages compared to the box method regarding the costs and the non-stationarity of the ABL. But the method requires the separation of the 
time and space dependence of the transported quantity (here the temperature $\theta$ ) in order to solve (5). This can be achieved with additional measurements e.g., with ground-based systems or more flight measurements, or both in combination, as demonstrated by Grunwald et al. (1998). Incidentally, the last method may induce wrong solutions due to local instead of global minima in the four-dimensional space (Tarantola, 1987). Of course the application of repeated flights or flights with parallel legs in perpendicular directions (grid pattern) would consume time and cause the loss of a big advantage of the method. With additional measurement systems on the ground in order to obtain the horizontal gradients and the temporal development, the strategy could not be applied autonomously but would depend on supporting equipment.

\section{Implementation of an Inverse Model}

\subsection{THE INVERSE MODEL}

To obtain a stand-alone procedure the low-level flights were combined with the inverse theory (e.g., Tarantola, 1987) to calculate the missing parameters in the budget equations. The inverse modelling technique uses a measured dataset $\vec{d}_{\text {obs }}$ of an atmospheric quantity and assumes a model relationship $G$ that describes physical processes of the quantity. The result of the inversion is a set of parameters $\vec{m}$ that reproduce the measured data when inserted into the model relationship $G$. In other words, the technique uses appropriate model assumptions that are based on theoretical assumptions to fit measured data. The inverse method was already applied to airborne measurements to describe arrays of meteorological quantities (Wolff and Bange, 2000).

For the enthalpy Equation (5) we assumed a linear relationship (linear operator $G$ ) between the model parameters $\vec{m}$ and the measurements $\vec{d}_{\text {obs }}$ :

$$
\begin{aligned}
\vec{d}_{\mathrm{obs}} & =G(\vec{m}) \\
& =m_{0}+m_{1} \vec{x}+m_{2} \vec{y}+m_{3} \vec{z}+m_{4} \vec{t},
\end{aligned}
$$

with

$$
\left(m_{1}, \ldots, m_{4}\right)=\left(\frac{\partial \vec{d}_{\mathrm{obs}}}{\partial x}, \ldots, \frac{\partial \vec{d}_{\mathrm{obs}}}{\partial t}\right) .
$$

In this equation, $\vec{x}, \vec{y}, \vec{z}$, and $\vec{t}$ represent data vectors containing the Cartesian coordinates and the time, respectively, as they were sampled during the measurement flight. The dimension of each data vector is $N$, the number 
of measured samples. The ratio of temporal to spatial dependence of the vertical flux divergence can later be expressed by

$$
A=\frac{m_{4}}{\bar{u} m_{1}+\bar{v} m_{2}} .
$$

For the turbulent sensible heat flux $H$, the data vector $\vec{d}_{\mathrm{obs}}(x, y, z, t)$ represents the set of measured potential temperatures $\theta$. To reproduce the potential temperature in this example, the inverse model was initialised with a realistic range of values of the mean potential temperature gradient and the mean temporal development of $\theta$. These values had to be estimated roughly from the synoptic situation and inserted into the vector $\vec{m}_{\text {prior }}$ (of dimension five, see Equations (7) and (8)) of a priori parameters. Their a priori uncertainties, the range in which the final (a posteriori, after the inversion) parameters $\vec{m}$ were expected, were written into the diagonal of the tensor $C_{M}$, the model covariance operator. An example for the $a$ priori quantities is given by Table I.

The statistical measurement errors were considered by the tensor $C_{D}$, which is defined as the sum of the statistical uncertainties $C_{d}$ of the sensors and statistical uncertainties $C_{T}$ of all assumptions made for the model. Since the latter is rather a fuzzy quantity, the definition of the whole experimental covariance operator $C_{D}$ is somewhat a matter of experience. However, the elements of $C_{D}$ represent the accuracy of the individual sensors and measurement systems plus a little extra for the necessary assumptions.

In addition to the linear relationship in (7) the statistical distributions of the measured data, the a priori, and the a posteriori uncertainties, were assumed to be Gaussian. This combination of internal conditions of the

TABLE I

$A$ priori values of the model parameters $m_{\text {prior }, i}$ and their uncertainties (variances) $C_{M}^{i i}$ for both the Helipod and the Do 128 flights during LITFASS-98.

\begin{tabular}{|c|c|c|c|c|c|}
\hline$i=$ & 0 & 1 & 2 & 3 & 4 \\
\hline & $\theta$ & $\partial \theta / \partial x$ & $\partial \theta / \partial y$ & $\partial \theta / \partial z$ & $\partial \theta / \partial t$ \\
\hline & $\mathrm{K}$ & $\mathrm{K} \mathrm{km}^{-1}$ & $\mathrm{~K} \mathrm{~km}^{-1}$ & $\mathrm{~K} \mathrm{~m}^{-1}$ & $\mathrm{Kh}^{-1}$ \\
\hline$m_{\text {prior }, i}$ & 285 & 0 & 0 & 0 & 1 \\
\hline \multirow[t]{3}{*}{$\sqrt{C_{M}^{i i}}$} & 10 & 0.1 & 0.1 & 0.01 & 1 \\
\hline & $q$ & $\partial q / \partial x$ & $\partial q / \partial y$ & $\partial q / \partial z$ & $\partial q / \partial t$ \\
\hline & $\mathrm{g} \mathrm{kg}^{-1}$ & $\mathrm{~g}(\mathrm{~kg} \mathrm{~km})^{-1}$ & $\mathrm{~g}(\mathrm{~kg} \mathrm{~km})^{-1}$ & $\mathrm{~g}(\mathrm{~kg} \mathrm{~m})^{-1}$ & $\mathrm{~g}(\mathrm{~kg} \mathrm{~h})^{-1}$ \\
\hline$m_{\text {prior }, i}$ & 7.5 & 0 & 0 & 0 & 0 \\
\hline$\sqrt{C_{M}^{i i}}$ & 1 & 0.1 & 0.1 & 0.01 & 2 \\
\hline
\end{tabular}

The values for $m_{0}$ were calculated using the mean values of the temperature and humidity measurements, respectively. All other $m_{i}$ were estimated. 
inversion is named $l_{2}$-norm (see Tarantola, 1987; Wolff and Bange, 2000, for more details). The big advantage of the $l_{2}$-norm is the comparatively simple inversion

$$
\vec{m}=G^{-1} \vec{d}_{\text {obs }}
$$

of the problem (7) within minutes on a state-of-the-art personal computer. The goal of the inversion was the minimisation of the so-called cost function

$$
\begin{aligned}
S(\vec{m})= & \left(G \vec{m}-\vec{d}_{\text {obs }}\right)^{T} C_{D}^{-1}\left(G \vec{m}-\vec{d}_{\text {obs }}\right) \\
& +\left(\vec{m}-\vec{m}_{\text {prior }}\right)^{T} C_{M}^{-1}\left(\vec{m}-\vec{m}_{\text {prior }}\right)
\end{aligned}
$$

of the problem. Note that the first term of the cost function refers to the least-square problem of a simple regression computation. The minimisation was actually done by calculating the a posteriori model parameter

$$
\vec{m}=C_{M^{\prime}}\left[G^{T} C_{D}^{-1} \vec{d}_{\mathrm{obs}}+C_{M}^{-1} \vec{m}_{\text {prior }}\right]
$$

directly, using the a posteriori covariance operator

$$
C_{M^{\prime}}=\left[G^{T} C_{D}^{-1} G+C_{M}^{-1}\right]^{-1} .
$$

The a posteriori covariance operator consists of the statistical uncertainties of the model parameters (their variances, which are equal to the squared standard deviations) placed in the diagonal $\left(C_{M^{\prime}}^{i i}\right)$, while the non-diagonal elements represent the cross-variance (covariances) between the individual parameters. Therefore the inverse model differs in (at least) two items from a regression: firstly, the a priori assumptions are considered as important information that attend the inversion. A first quality criterion of a successful inversion is whether the a posteriori parameters stay within the physical boundaries given by the a priori covariance operator $C_{M}$. Secondly, the a posteriori covariance operator $C_{M^{\prime}}$ discloses correlations between the (assumed to be independent) parameters $m_{i}$.

\subsection{Model QUALITY CONTROL}

An important advantage of the inverse model against normal regression calculation is that it provides simple methods to test the quality of the inversion. Some of these criteria were already discussed in Wolff and Bange (2000). It turned out that for the airborne flux measurements six criteria were useful:

1. Variances reduced: the variances of the model parameters represent the statistical uncertainties of the model (before and after the inversion). 
TURBULENT SURFACE FLUXES FROM LOW-LEVEL FLIGHTS USING INVERSE MODELS

The a posteriori variances $C_{M^{\prime}}^{i i}$ had to be smaller than the a priori variances $C_{M}^{i i}$.

2. Parameters inside range: the a posteriori model parameters $m_{i}$ had to be within the range of the a priori variances $C_{M}^{i i}$. This ensures that the inversion did not leave the initially set physical boundaries of the model parameters.

3. The $\chi^{2}$-test for data: following the considerations of Tarantola (1987) the expression

$$
\chi_{d}^{2}=\sum^{N} \frac{\left(\vec{d}_{\mathrm{obs}}-\vec{d}_{m}\right)^{2}}{\sigma_{d}^{2}}
$$

(with the number $N$ of measurements) had to be $\leq 1$. The forward-modelled time series $\vec{d}_{m}$ was defined by

$$
\vec{d}_{m}=G \vec{m}
$$

The difference between the observed data $\vec{d}_{\text {obs }}$ (i.e., the temperature $\theta$ or the humidity $m$, respectively) and the modelled data series had to be smaller than the measurement error plus the uncertainty of the model assumption $\sigma_{d}^{2}$ of the instrument. The variance $\sigma_{d}^{2}$ is an element of the operator $C_{D}$. If $\chi_{d}^{2} \ll 1$, then the model run was correct but the uncertainty $\sigma_{d}^{2}$ was chosen too large.

4. Visual check: a very important test is the visual comparison of the modelled with the measured time series. Even if the $\chi^{2}$ data test gave values close to unity in some cases the modelled data did not follow the measurements satisfactorily. An example for both the observed and the forward-modelled time series is given in Figure 2. Of course the turbulent fluctuations of the measured data could not be reproduced by the inversion. Apart from that the modelled data agreed well with the observations.

5. The $\chi^{2}$-test for parameters: this test follows the $\chi^{2}$-test for the dataset:

$$
\chi_{m_{i}}^{2}=\frac{\left(m_{\mathrm{prior}, i}-m_{i}\right)^{2}}{C_{M}^{i i}}
$$

must be $<1$. The difference between the a priori and the a posteriori model parameters had to be smaller than the a priori variances $C_{M}^{i i}$. A good model setting was chosen when $0.2<\chi_{m_{i}}^{2}<1$. If $\chi_{m_{i}}^{2}$ was much smaller than unity the uncertainty of the a priori model parameters was chosen too large.

6. Un-correlation: the a posteriori covariances $C_{M^{\prime}}^{i j}$ (with $i \neq j$ ) represent the correlations between the model parameters. These should be small, with largest accepted values around 0.6. 

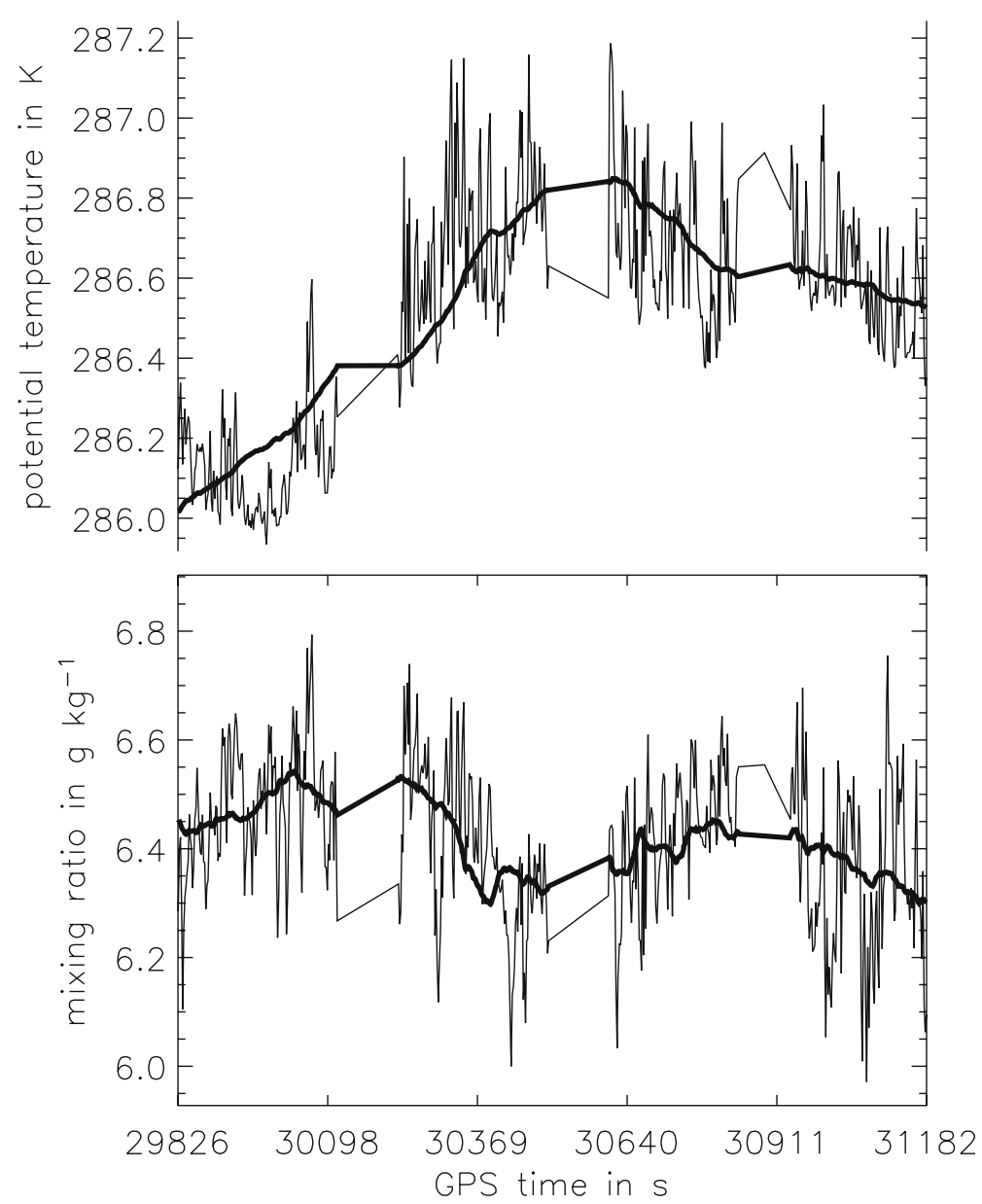

Figure 2. Times series of potential temperature and mixing ratio. Thin lines: measured data (four legs of a Helipod box flight) from the LITFASS-98 experiment. Bold lines: forward-modelled data. Note the three sections of missing data in the measured time series due to turning of the Helipod after each leg. The first leg was flown westwards, the second southwards, the third eastwards, and the last northwards to build a square-shaped flight pattern.

While the first five criteria were easy to handle, the last one was somewhat more difficult to apply. On a short flight (e.g. a box pattern that consisted of $15-\mathrm{km}$ legs) in the CBL the model could not always clearly distinguish between the time (parameter $m_{4}$ ) and one of the horizontal directions $\left(m_{1}\right.$ or $m_{2}$, respectively). In that case it depended on the test results of the other five criteria to decide whether the inversion was successful or not. Of course the interpretation of the inversion results became easier when it was applied to large flight patterns, such as grids that contained about 20 legs of 15-km length (Spieß et al., 2004). 


\subsection{THE APPLICATION TO AIRBORNE MEASUREMENTS}

After the application of the inverse model to airborne temperature measurements the output $\vec{m}$ of the inversion provides the gradient and the temporal development of the mean potential temperature. The vertical gradient of the heat flux can then be calculated by inserting the parameters into (5). Finally the surface heat flux is calculated using (6). Of course this method can also be used for the latent heat flux and other vertical scalar fluxes as long as a functional relationship between the flux and the height below the flight altitude can be assumed. The combination of low-level flights with an inverse model (LLF+IM) allows therefore the determination of the areaaveraged turbulent surface fluxes from square-shaped flight patterns at only one low altitude (e.g. at $z_{f}=100 \mathrm{~m}$ or less) without any supporting data from other systems.

\section{Statistical Errors of Turbulent Fluxes}

Before the verification of the LLF + IM is presented the method to calculate the statistical errors of the turbulent fluxes is briefly explained. The method introduced here provided significantly smaller statistical errors in comparison with what we refer to as the 'usual' procedure. In the following all calculations are made for the sensible heat flux $H$. A very similar method was used to calculated the statistical error of the latent heat flux $\lambda E$.

First, the statistical uncertainty $\sigma_{H_{0}}$ of the resulting extrapolated surface sensible heat flux $H_{0}$ was defined by the involved individual uncertainties. Following (6), these are $\sigma_{H}$ for the heat flux $H_{z f}, \sigma_{z}$ for the flight level $z_{f}$, and $\sigma_{\delta}$ for the vertical flux divergence $\partial H / \partial z$. Assuming Gaussian distributed uncertainties the propagated error was calculated as

$$
\sigma_{H_{0}}^{2}=\sigma_{H}^{2}+\left(z_{f} \sigma_{\delta}\right)^{2}+\left[\left(\frac{\partial H}{\partial z}\right) \sigma_{z}\right]^{2} .
$$

The uncertainty $\sigma_{\delta}$ was derived from the uncertainties (13) of the model parameters $m_{i}$ inserted into (5), also assuming Gaussian error propagation. The standard deviation $\sigma_{z}$ of the aircraft altitude was directly derived from the navigation data. The statistical error $\sigma_{H}$ of the measured flux (here heat flux $H$ at flight level $z_{f}$ ) was calculated with the following procedure.

According to Lenschow and Stankov (1986) the error variance of the kinematic flux $f$ is given by

$$
\sigma_{f}^{2}=2\left(\frac{I_{f}}{L}\right)\left\langle f^{\prime 2}\right\rangle,
$$


where $L$ represents the length of one flight leg and $f$ the product of the vertical wind fluctuations $w^{\prime}$ with the potential temperature fluctuations $\theta^{\prime}$, i.e.

$$
f(t)=w^{\prime}(t) \theta^{\prime}(t) .
$$

The prime denotes that the mean value and the linear trend were subtracted from the time series. The integral length scale $I_{f}$ was calculated by integrating the auto-correlation function of $f$ between zero lag and the first zero crossing of the function at lag $\tau_{1}$ :

$$
I_{f}=V_{\mathrm{tas}} \int_{0}^{\tau_{1}} d \tau \frac{\left\langle f^{\prime}(t+\tau) f^{\prime}(t)\right\rangle}{\left\langle f^{\prime 2}\right\rangle}
$$

(Lumley and Panofsky, 1964; Lenschow and Stankov, 1986) with the true air speed of the aircraft $V_{\text {tas }}$. In contrast to some studies that define the integral length scale via the cross-correlation function of $w$ and $\theta$, this analysis uses the definition of Lenschow et al. (1994, Section 3b), for the random statistical error of fluxes. The latter defined also a systematic statistical error that was found one order of magnitude smaller than $\sigma_{f}$ for the data presented here, and was therefore neglected (Bange et al., 2002).

Often the integral scale is hard to calculate since the correlation function behaves unpredictably (e.g., Mann and Lenschow, 1994). Therefore estimations for $I_{f}$ are common and often required (e.g., Lenschow et al., 1994). This was found to be unnecessary for the flight data presented here. The integral scales $I_{f}$ used within this work were directly calculated using (20) without any approximations. Furthermore no Gaussian distribution for time series was assumed and no approximation as suggested by Lenschow and Stankov (1986) was applied. In fact, the statistical flux error (18) was directly calculated (according to Equation (6) in Lenschow and Stankov, 1986) using

$$
\sigma_{H}=2 \rho c_{p} \frac{I_{f}}{L}\left(\left\langle w^{\prime^{2}} \theta^{\prime^{2}}\right\rangle-\left\langle w^{\prime} \theta^{\prime}\right\rangle^{2}\right) .
$$

The use of the non-approximated Equations (20) and (21) led to smaller statistical flux errors compared to the application of the 'usual', approximated equations (Zittel et al., 2004). As Figure 3 demonstrates the error reduction was up to $50 \%$. The excellent agreement of Helipod and Do 128 flux measurements at identical altitudes (Section 5.2) confirm that the smaller errors were not only mathematically correct but also credible. Also Isaac et al. (2004) found smaller length scales than predicted by Lenschow and Stankov (1986).

In the following the LLF + IM method is verified using simulated flight measurements in a large-eddy simulation, a comparison with the box 
TURBULENT SURFACE FLUXES FROM LOW-LEVEL FLIGHTS USING INVERSE MODELS

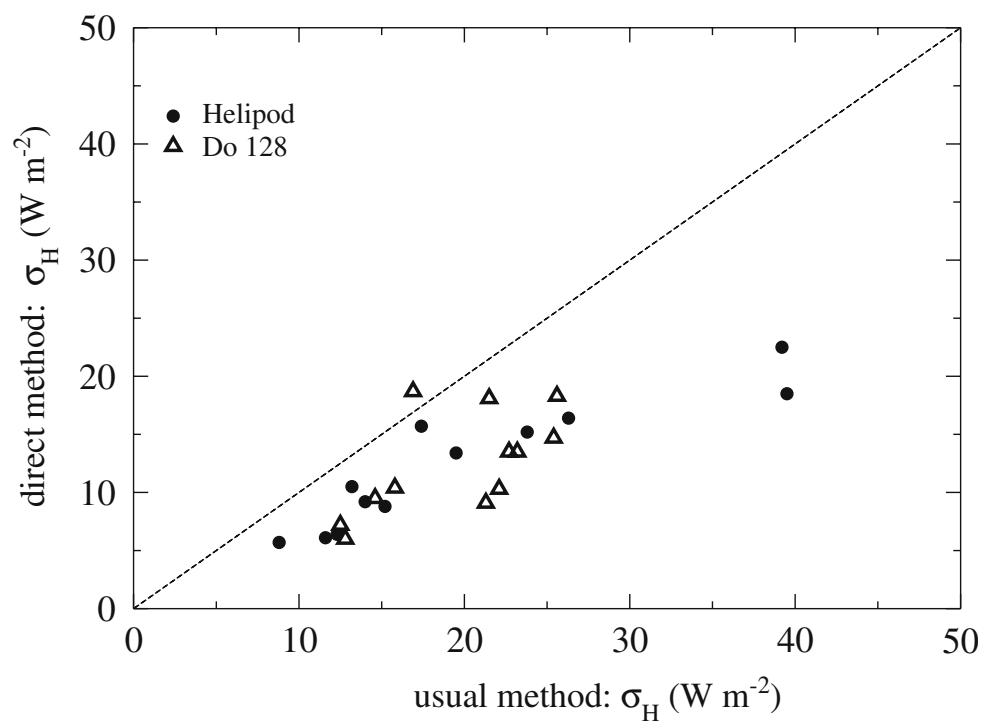

Figure 3. Comparison of the calculated statistical flux errors on Do 128 and Helipod flight legs during LITFASS-98. A linear interpolation of the data gives a line (not drawn) with about 0.7 slope.

method and the results of two different airborne systems (LITFASS-98 experiment), and ground-based measurements (LITFASS-2003 field campaign).

\section{Verification of the Method}

\subsection{LARGE-EDDY SIMULATION}

To verify the LLF + IM method with simulated flight measurements above homogeneous and heterogeneous terrain (see also Schröter et al., 2000) the large-eddy simulation (LES) model PALM (Raasch and Schröter, 2001) was employed. PALM is based on the non-hydrostatic incompressible Boussinesq equations. In total, prognostic equations for $u, v, w$, the liquid water potential temperature, the total water content, and the subgrid-scale kinetic energy were solved with a leap-frog time-step scheme for these simulations. The subgrid-scale kinetic energy was modelled according to Deardorff (1980). Incompressibility was ensured by the solution of a Poisson equation for pressure after each timestep, which was realized by the Singleton-FFT method. For the advection terms, the scheme of Piacsek and Williams (1970) was used. Furthermore, Monin-Obukhov similarity was assumed between the surface and the first vertical grid points. The lateral boundary conditions of the model were cyclic. 
Two types of model runs were performed. The homogeneous simulation was forced by the prescription of a constant surface sensible heat flux of $151 \mathrm{~W} \mathrm{~m}^{-2}$. For the idealised heterogeneous run a constant, checkerboardtype surface sensible heat flux (patch size $6 \mathrm{~km}$; 'white patches' heated with $88 \mathrm{~W} \mathrm{~m}^{-2}$, 'black patches' with $214 \mathrm{~W} \mathrm{~m}^{-2}$ resulting in a mean of $151 \mathrm{~W} \mathrm{~m}^{-2}$ ). A similar set-up was introduced by Raasch and Harbusch (2001).

For both cases, a background wind of $5 \mathrm{~m} \mathrm{~s}^{-1}$ and a slightly stable initial profile of the potential temperature was applied. The model domain was $12 \mathrm{~km} \times 12 \mathrm{~km} \times 1.2 \mathrm{~km}$ with a horizontal (vertical) grid spacing of $40 \mathrm{~m}(20 \mathrm{~m})$. The virtual flights were carried out after $1.5 \mathrm{~h}$ simulation time, when the CBL was well developed. The subsequently analysed area and time-averaged turbulent fluxes were derived directly from the simulations. These 'true' data were then used to quantify any errors of the inverse method and deviations from the simulated 'truth'.

The temporal development of the thermal stratification is depicted in Figure 4. The vertical profiles were sampled at the beginning, in the middle, and at the end of the flight simulations, respectively. For the same dates Figures 5 and 6 show the 10-min and horizontally averaged vertical sensible heat fluxes of the LES for the homogeneous and the heterogeneous run, respectively. The CBL height (height of the minimum sensible heat flux) was ascending from 800 to $1000 \mathrm{~m}$ between 1.5 and $3.5 \mathrm{~h}$ simulation time.

LES, homogeneous terrain

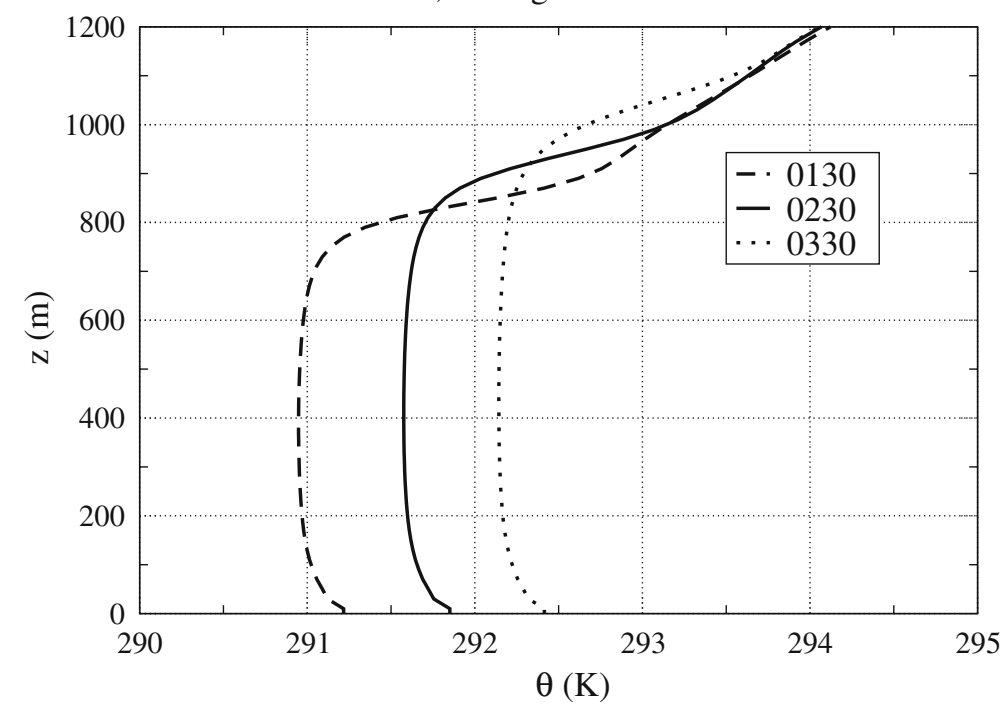

Figure 4. Development of the CBL during the simulated flights in a LES over heterogeneous terrain. The first curve was sampled at the beginning of the measurement flights $(1.5 \mathrm{~h}$ after simulation start), next after one hour of flights, last after two flight hours. 


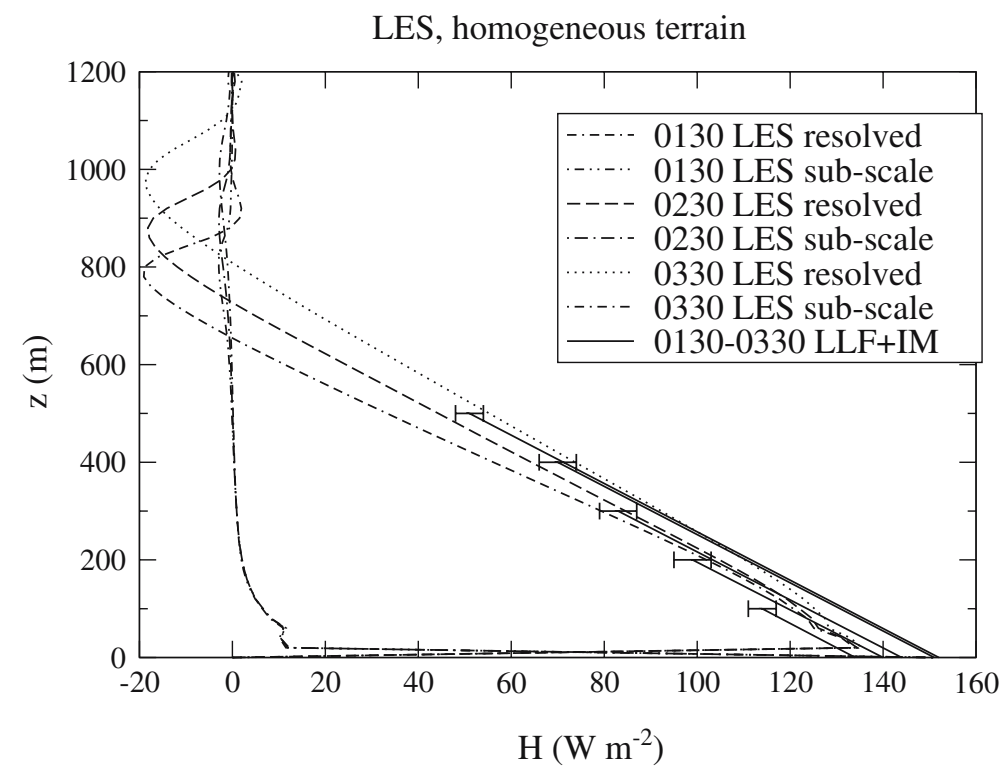

Figure 5. Comparison of the area-averaged turbulent fluxes calculated from virtual flights (marked with error bars) with the 'true' data from LES. This LES run was performed above a homogeneous surface. The resolved area- and time-averaged 'true' fluxes of the LES during the simulated flights are plotted with hourly intervals, as well as the subgrid flux. The extrapolations of the simulated flight measurements to the ground using the LLF + IM method are depicted by solid lines for each flight level.

The area- and time-averaged flux profiles were then treated as 'truth' for the comparison with simulated flight measurements. It should be recalled that the LES parameterised fluxes on scales smaller than the grid spacing of $40 \mathrm{~m}$, in this case. Therefore the flux diagrams (Figures 5 and 6) contain for each date a pair of curves: (1) the resolved flux (by solving the Navier-Stokes equation) and (2) the subgrid flux which had to be parameterised. The subgrid flux increased towards the surface due to unresolved small-scale and microscale eddies in this region. For the comparison with the simulated measurement flights only the resolved flux could be used since this was the flux collected and computed (using eddy covariance) by the simulated aircraft.

Within the LES model virtual measurement flights were performed using a horizontal box pattern with legs of $8-\mathrm{km}$ length. One horizontal box took $800 \mathrm{~s}$ simulated time and contained 800 measurements with $40-\mathrm{m}$ separation to each other along the flight path. Each square was flown nine times at $40 \mathrm{~m} \mathrm{~s}^{-1}$ ground speed. So, in total, flight measurements during $2 \mathrm{~h}$ were simulated. The flights were performed simultaneously at five altitudes $(100-500 \mathrm{~m}$ in $100-\mathrm{m}$ steps) within the artificial CBL. Those five virtual aircraft started their measurement flights after 90 min simulated time. 
J. BANGE ET AL.

LES, heterogeneous terrain

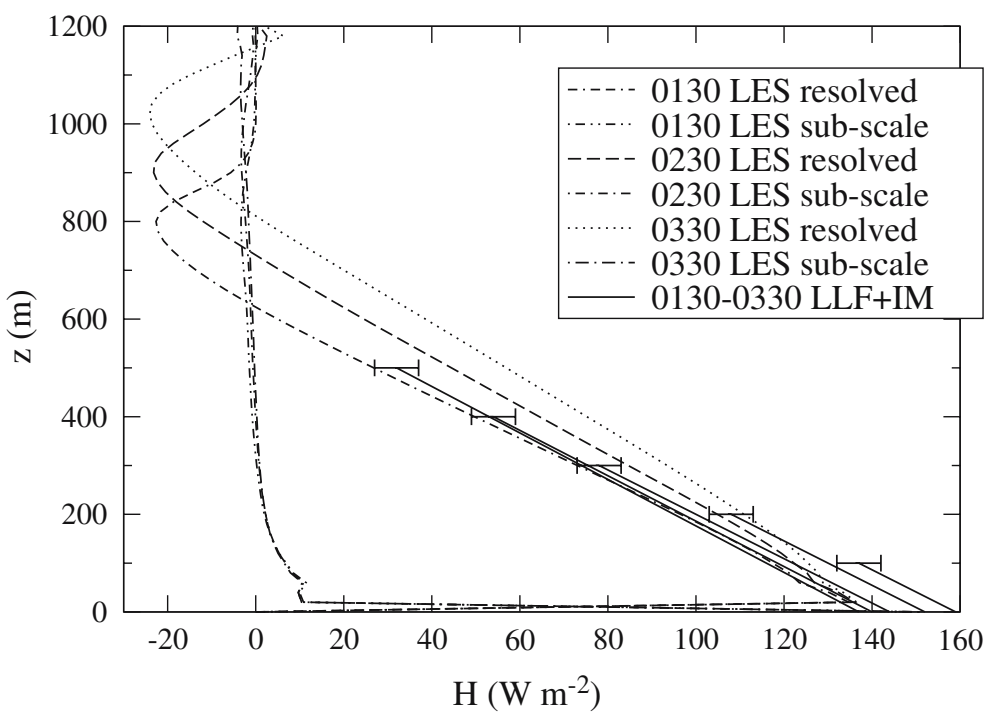

Figure 6. Vertical flux profile during a LES run above a heterogeneous surface. For explanations see Figure 5.

For each virtual aircraft the vertical turbulent heat flux $H$ was calculated using (1) with $n=4 \times 9$, as well as its statistical error (Section 4). The results are depicted as horizontal error bars in Figure 5 and 6. During the run above a homogeneous surface the 'true' averaged flux was slightly overestimated by the simulated flights in the middle of the CBL, and underestimated at flight levels close to the ground. During the LES run above the heterogeneous surface the airborne measurements slightly underestimated the flux at the centre of the CBL, and overestimated it near the ground. The reason for the discrepancies may be found in the nature of the averaging strategies. While the 'true' fluxes were averaged over the entire area but only over ten minutes, the 'airborne-measured' fluxes were collected and averaged during two-hour flights but only on square-shaped paths. These discrepancies of about $10 \%$ were not found during simulated flight measurements in the past (Schröter et al., 2000) that used a different flight strategy and was probably more representative.

Due to the nature of the applied LES neither the homogeneous nor the heterogeneous model run produced a mean horizontal temperature gradient. All fluctuations due to convection or the heterogeneous surface finally vanished after averaging over the entire model area and a sufficient period. Touchstone for the inverse model applied to the data collected during the simulated flights was therefore to identify a correct temporal dependence while all spatial parameters $m_{1}$ to $m_{3}$ (Equation (8)) had to be found close 


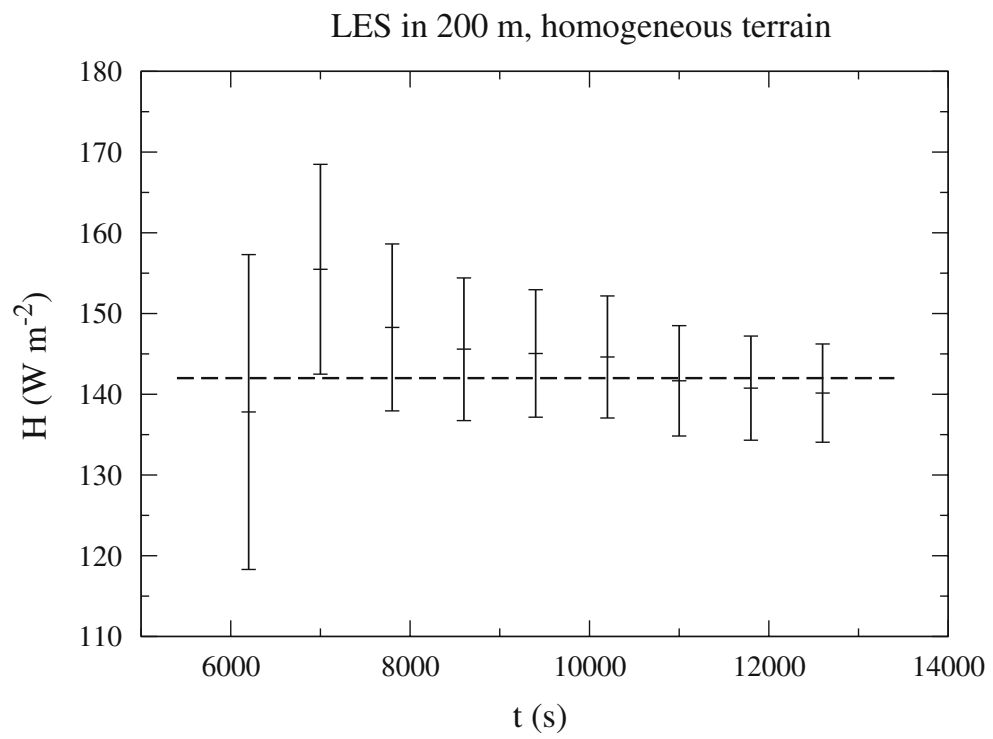

Figure 7. Temporal development of the difference between simulated airborne flux measurements and LES 'truth' (LES resolved flux, dashed line). The data points with error bars represent the averaged flux from completed square-shaped horizontal flight patterns at $200 \mathrm{~m}$ altitude, extrapolated to the surface. Each box flight pattern consisted of 800 point measurements.

to zero. Furthermore very small correlation between the parameters $m_{i}$ had to be expected.

These criteria were thoroughly fulfilled for all runs at all levels. Correlations were about $2 \%$ after the first horizontal flight pattern and significantly smaller than $1 \%$ after a few repetitions. The ratio $A$ of temporal to spatial dependence was always about 6300 at $100 \mathrm{~m}$ and decreased to 5000 at $500 \mathrm{~m}$. This was probably due to larger convective elements and therefore larger statistical uncertainty in the middle of the CBL. Also, the model quality criteria indicated that it was impossible for the inverse model to calculate a vertical temperature dependence since the altitude of the idealised flights in the LES did not fluctuate as with a real aircraft. As a result of the inversion the vertical gradients $\partial H / \partial z$ of the 'airborne-measured' fluxes agreed well with the 'true' gradients of the LES. The extrapolations to the ground (Equation (6)) from all five flight levels (solid lines in Figures 5 and 6) led, to surface fluxes close to the preconditioned 'true' values. The differences at ground level were all caused by the discrepancies at flight level. To sum up, the LLF + IM method worked well in the LES except for a not very accurate flight strategy that yield fluxes with $10 \%$ deviation to the area average at the flight level.

Figure 7 shows the temporal development of the extrapolated surface heat flux derived from airborne measurements using LLF + IM. This 


\section{J. BANGE ET AL}

example uses data collected at $200 \mathrm{~m}$ altitude, where the discrepancy between 'true' and 'airborne-measured' data was minimum. Whenever a single horizontal flight box at this height was finished, the turbulent flux was calculated using (1) by averaging over all legs that were completed so far. Then the surface flux was calculated using the LLF + IM method; i.e. the data point at $8600 \mathrm{~s}$ simulated time (no. 4, equivalent to $3200 \mathrm{~s}$ flight time since the flights started after $90 \mathrm{~min}$ of simulation) was calculated using the data collected during $4 \times 4$ legs, since four entire horizontal boxes were accomplished. The measurements converged to a value that was a few $\mathrm{W} \mathrm{m}^{-2}$ below the two-hour averaged requirement of the LES at the same height. The 10\% deviation mark was reached after the second box (1600s). The statistical error bar decreased continously but reached a more or less constant value of about $7 \mathrm{~W} \mathrm{~m}^{-2}$ during the last three boxes. This and the fall beneath the required value near the end of the two-hour flight measurements may be explained by the comparatively short flight legs. While the LES is able to produce significant convective structures of several kilometres size, the virtual aircraft may not measure these very large structures with sufficient statistical accuracy (Lenschow and Stankov, 1986). Also, the flight pattern was probably not representative of the entire area as explained above.

\subsection{THE LITFASS-98 FLIGHT COMPARISON}

The LITFASS-98 experiment (Beyrich et al., 2002c) was performed in May and June 1998, in a heterogeneous landscape around the Meteorological Observatory Lindenberg (MOL) of the German Meteorological Service (Deutscher Wetterdienst, DWD). One intention of the experiment was to test a strategy for the determination of area-averaged turbulent surface fluxes at the scale of a grid box of a regional numerical weather prediction model. LITFASS-98 included flux measurements at several micrometeorological ground stations and at a 99-m meteorological tower using the eddy-covariance methods. Area-representative sensible heat fluxes were obtained from the operation of a large-aperture scintillometer (Beyrich et al., 2002b) and from the analysis of wind profiler/RASS measurements (Engelbart and Bange, 2002). Within LITFASS-98, a one-day flight experiment was carried out on 18 June 1998, designed to compare area-averaged fluxes from two airborne systems (Do 28 and Helipod) with the groundbased flux estimates (Bange et al., 2002).

The Helipod is a turbulence probe that travels at $40 \mathrm{~m} \mathrm{~s}^{-1}$ attached to a rope under a helicopter. At $100 \mathrm{~Hz}$ sampling rate the Helipod measures the atmospheric wind vector, the humidity, and air and surface temperatures; see Spieß et al. (2004), Bange and Roth (1999), Roth et al. (1999), Muschinski and Wode (1998). The Do 128 is a twin-engined 
research aircraft that travels at $60 \mathrm{~m} \mathrm{~s}^{-1}$ and is equipped with a nose boom containing the fast meteorological measurement systems (Hankers, 1989). The equipment for measuring the air dynamics was renewed after the LITFASS-98 campaign (Corsmeier et al., 2001).

For the determination and comparison of the area-averaged turbulent fluxes, the flights were performed simultaneously in two box patterns. The inner box $(10 \mathrm{~km} \times 10 \mathrm{~km})$ was flown by the Helipod at about 77, 390, and $700 \mathrm{~m}$ above ground level (agl) and consisted therefore of three horizontal, square-shaped runs (named hbox 1 to hbox3). The outer box $(15 \mathrm{~km} \times$ $15 \mathrm{~km}$ ) was flown by the Do 128 (dbox1 to dbox3) at 200, 390, and $700 \mathrm{~m}$. The length of the Do 128 and Helipod legs reflected the air speed ratio of the two airborne systems. The simultaneous flights started at around 0918 local time (0718 UTC) and were carried out in the developing CBL for the next $1.5 \mathrm{~h}$. Half an hour before that an extra horizontal square was flown by the Do 128 (dbox0).

During the experiment the turbulent fluxes of sensible and latent heat, as well as the momentum flux, were almost identical for Helipod and Do 128 measurements at the same altitude (Bange et al., 2002). The actual differences were clearly smaller than the statistical errors of most of the measured fluxes.

\subsubsection{The Sensible Heat Flux}

In a first analysis the turbulent flux of sensible heat at the surface was determined from airborne measurements by linear extrapolation of the fluxes measured on the box flights hbox 1 to 3 and dbox1 to 3 (box method), respectively. The CBL had just commenced its development since the flights were performed in the morning hours; the CBL growth during the time of the flight was approximately linear, on the average, but with larger fluctuations in time and space (Bange et al., 2002). Therefore the scaling of the height axis, in order to apply the box method, was probably not very precise. This reduced the accuracy of the box method in addition to the systematic error described in Section 2.1.

Although the flux measurements at each of the upper two levels were nearly identical, the two linear interpolations of the Helipod and the Do 128 measurements were not parallel and led to dissimilar surface fluxes with $25 \mathrm{~W} \mathrm{~m}^{-2}$ discrepancy (Figure 8). This was probably due to the underlying, very heterogeneous surface. Do 128 and Helipod flew over different terrain that had the largest influence at the lowest flight levels. Nevertheless both extrapolations were still within the large uncertainty range of the ground-based measurements $\left(110 \mathrm{~W} \mathrm{~m}^{-2}\right.$ with $50 \%$ statistical error). While the extrapolation of the Helipod measurements (which agreed well with tower measurements at the same height and with the scintillometer measurements near the surface) underestimated the averaged 


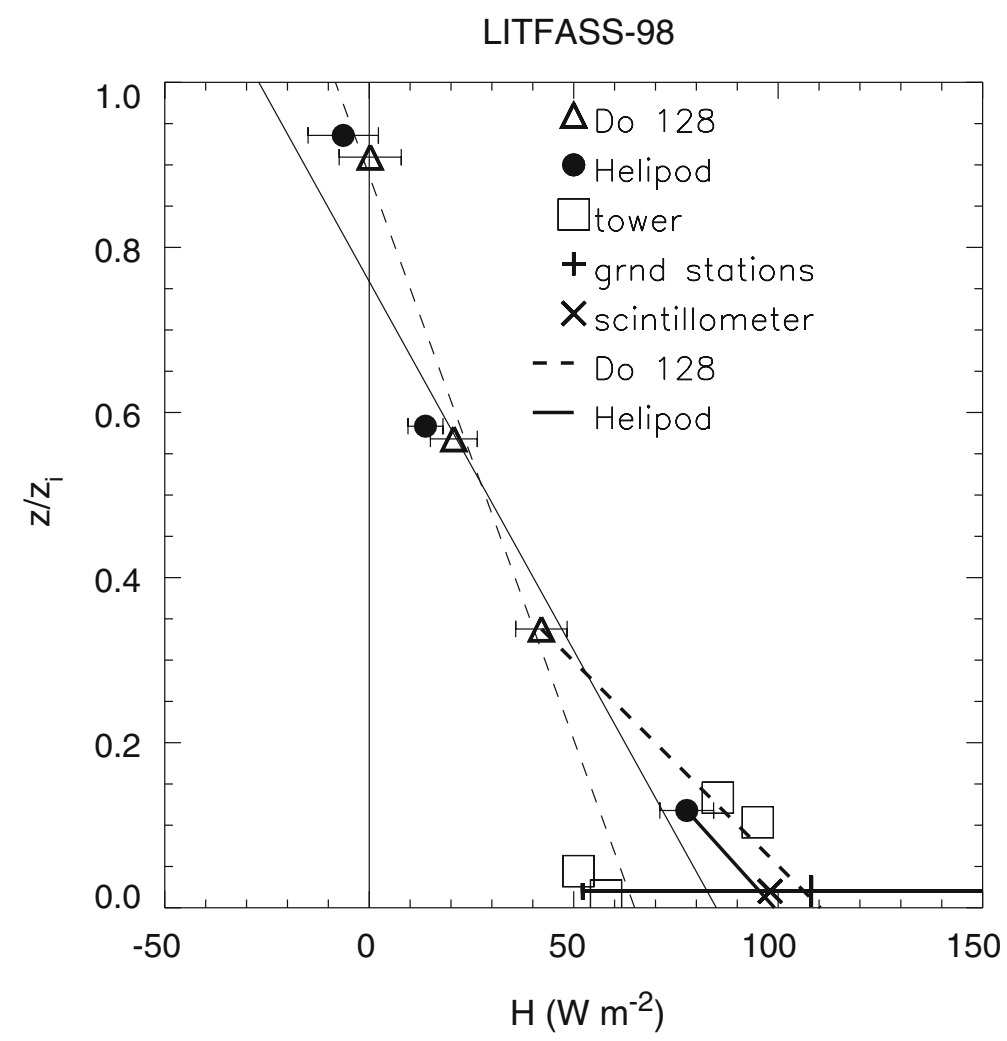

Figure 8. Sensible heat fluxes measured in LITFASS-98. Do 128 and Helipod measurements (dbox 1 to dbox3, hbox 1 to hbox 3 ) are represented by triangles and circles, respectively. The interpolations of the box flight patterns are depicted as black thin lines. The extrapolation using the LLF + IM method is displayed by thicker lines (dashed: Do 128; solid: Helipod measurements, respectively).

ground-based measurements by $20 \mathrm{~W} \mathrm{~m}^{-2}(18 \%$ deviation from the ground average), the results from the Do 128 measurements showed even larger deviations $\left(50 \mathrm{~W} \mathrm{~m}^{-2}\right.$ or $45 \%$ from the ground average).

For the testing of the LLF + IM the lowest flight levels of both the Helipod (hbox1) and the Do 128 (dbox0 and dbox1) were used. To point out the limits of the method, flights near the middle of the CBL were analysed as well (dbox 2 and hbox2). The upper flight legs (hbox 3 and dbox 3 ) were too close to the inversion to allow a linear extrapolation to the ground. The absolute temperature measurement accuracy (including the uncertainty of the model assumptions) was set to $\sigma_{d}=0.2 \mathrm{~K}$ for both the Do 128 and the Helipod. The results are listed in Table II. It transpired that some model parameters (terms in Equation (5)) were in good agreement. Especially the temporal development of $m_{4}$ and the north-south component $m_{2}$ were quite constant for all flights and altitudes. The west-east component 
TURBULENT SURFACE FLUXES FROM LOW-LEVEL FLIGHTS USING INVERSE MODELS

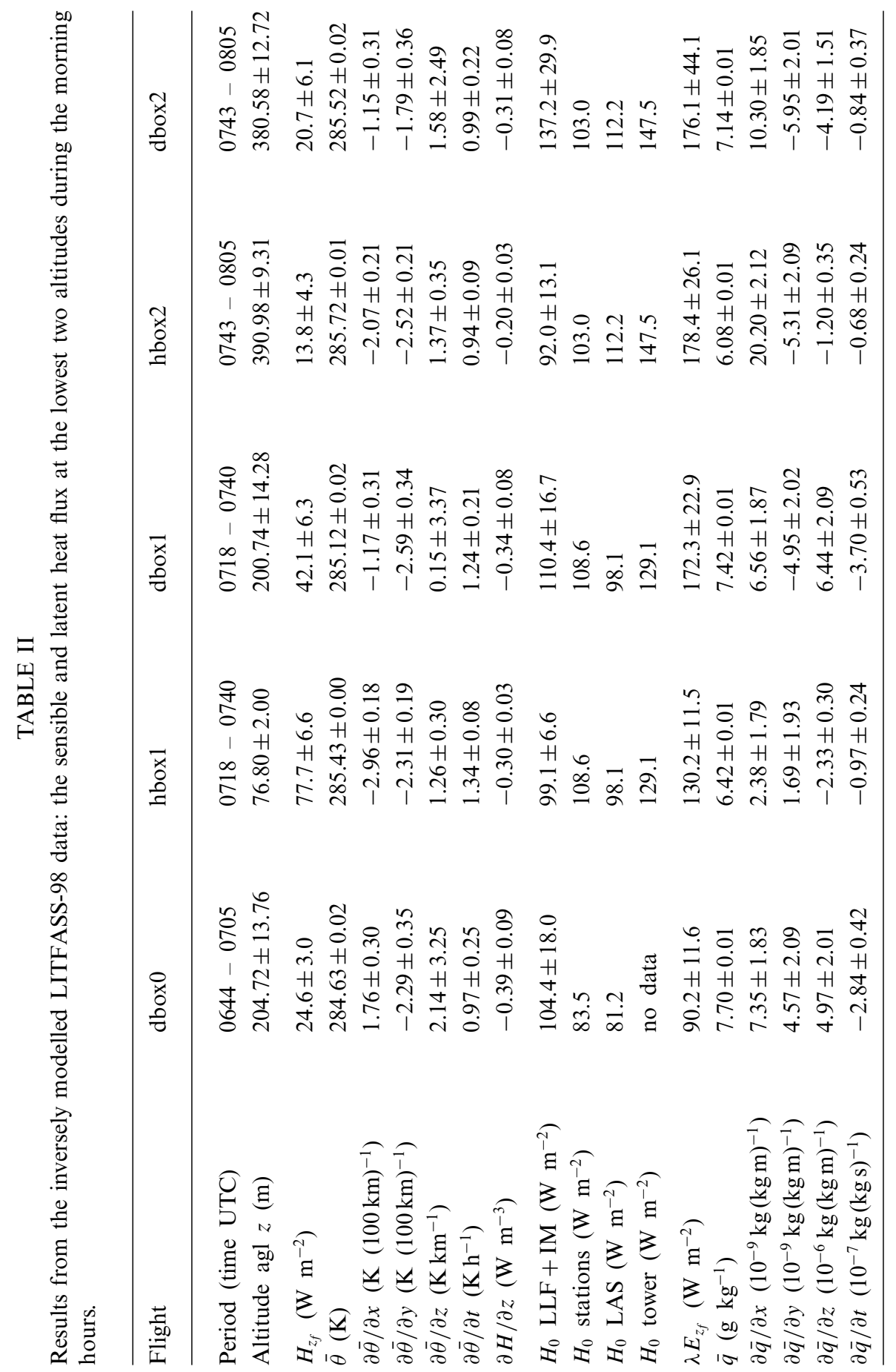


J. BANGE ET AL.

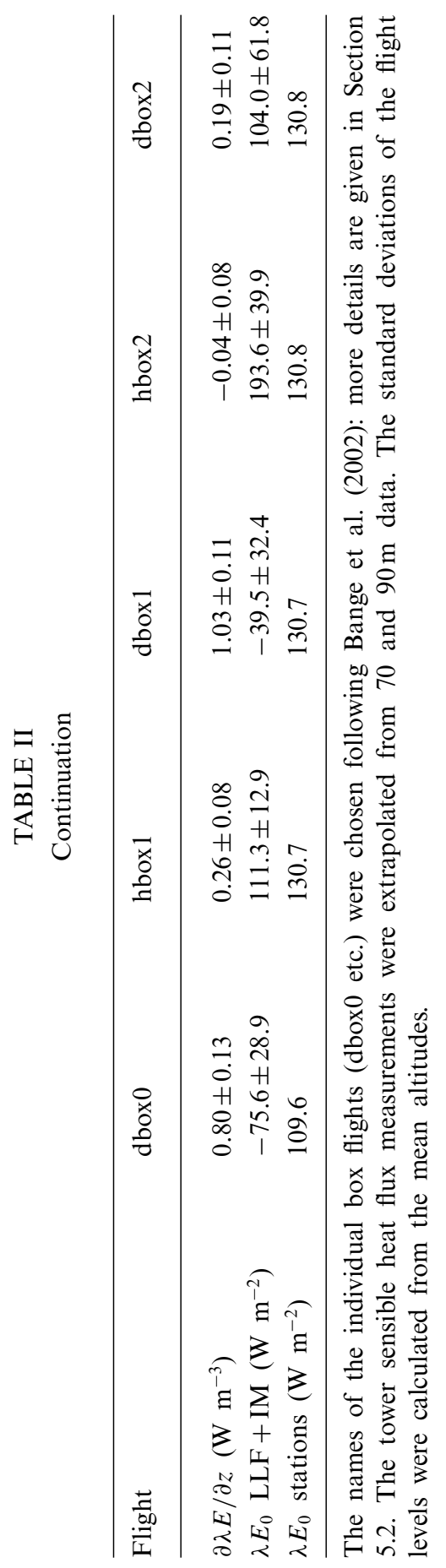


$m_{1}$ differed nearly by a factor of two even between simultaneous flights at the same altitude. The vertical component $m_{3}$ was very uncertain for all three Do 128 flights, but this was unimportant for further calculations. However, the vertical divergence of the heat flux (5) as a function of $m_{1}$, $m_{2}$, and $m_{4}$ was found to be similar for all five flights leading to plausible surface heat fluxes $H_{0}$ by using (6). The smallest relative uncertainty of the surface heat flux was found with $6.7 \%$ for the lowest flight, i.e. the Helipod measurements at $77 \mathrm{~m}$ agl. This was followed by the two Do 128 at $200 \mathrm{~m}$ agl and the second Helipod flight at $390 \mathrm{~m}$ (all between 14 and 17.5\%). The second Do 128 level yielded an unacceptable uncertainty of $22 \%$.

Table II also lists the averaged observations of the ground-based systems (ground stations, large-aperture scintillometers LAS, and the extrapolated upper two tower measurements). The tower measurements were only representative in the direct vicinity of the tower installation, and the LAS for a $4.7 \mathrm{~km}$ long strip. The averaged ground-station measurements provided for sure the most area-representative ground data, but there was substantial non-stationarity in the surface fluxes that caused larger uncertainty. Therefore it was difficult to define 'ground-truth' data for the comparison with the airborne measurements. However, the derived sensible surface heat fluxes from airborne measurements agreed within their statistical uncertainties (error bars) and with the averaged ground data.

As expected the smallest uncertainty was achieved at the lowest altitude. The extrapolation to the surface from the lowest two simultaneous flights (dbox 1 and hbox 1 ) is plotted in Figure 8. In comparison with the box method the LLF + IM method led to clearly improved results. Both extrapolations of the lowest flights had identical slopes. The extrapolation of the Do 128 measurement met both upper level tower measurements. The difference between the two extrapolated flight measurements was about $10 \mathrm{~W} \mathrm{~m}^{-2}$ at the surface level. The difference to the averaged ground-station measurements was close to zero for the Do 128 measurements. The extrapolated Helipod measurements met nearly perfectly the LAS observations.

\subsubsection{The Latent Heat Flux}

For the determination of the latent heat flux in LITFASS-98 the box method worked almost perfectly (Figure 9). The Helipod and Do 128 measurements at four different altitudes gave a remarkable near-linear profile of the latent heat flux, which, for sure, is not typical for the ABL (Chou et al., 1985; Scherf and Roth, 1997; Grunwald et al., 1998; Brümmer and Thiemann, 2002). In our situation the linear extrapolation of the airborne measurements agreed well with the measurements of the ground stations and the two lowest tower stations (in LITFASS-98, no moisture fluxes were available from the upper two tower levels). Since the groundbased latent heat flux measurements at the various locations within the 


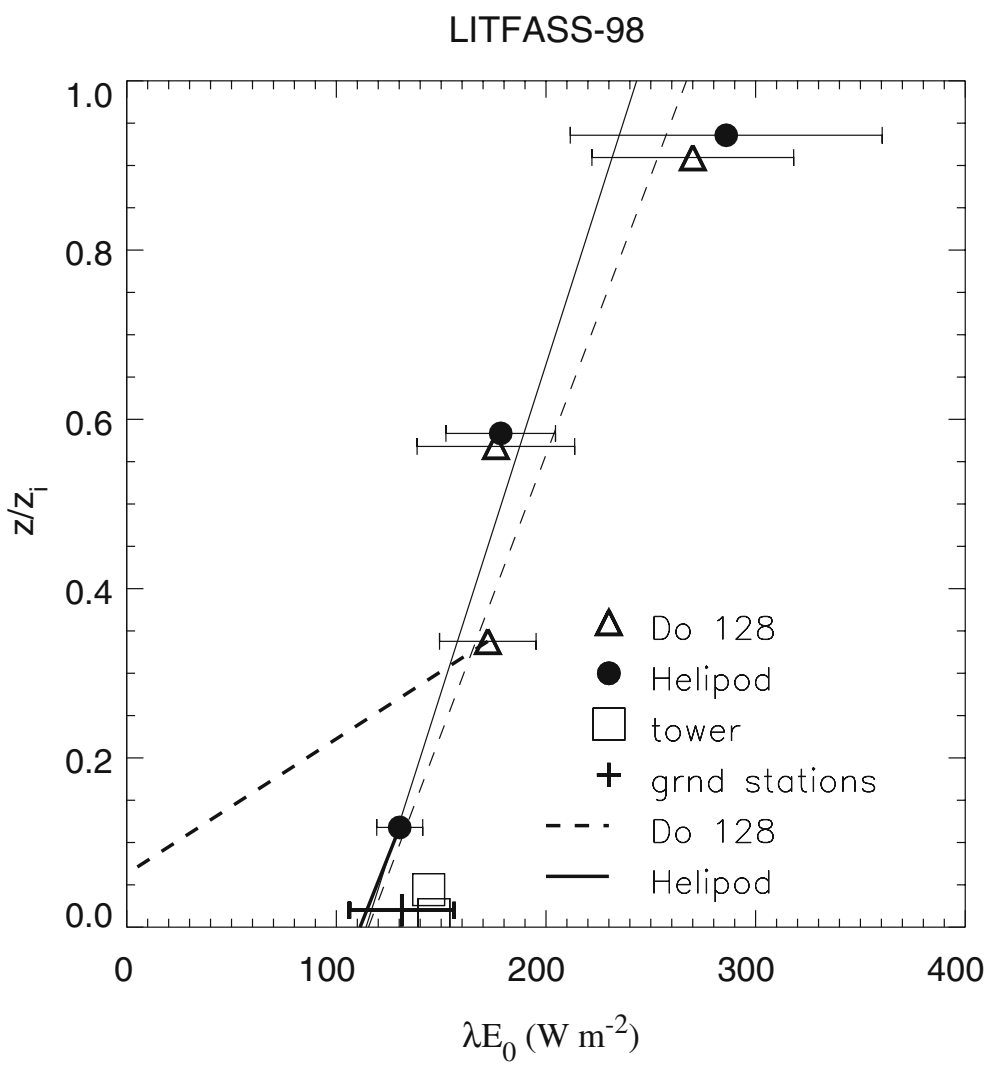

Figure 9. Latent heat fluxes measured in LITFASS-98. For explanations, see Figure 8.

experimental site did not vary much, the statistical uncertainty was only about $\pm 25 \mathrm{~W} \mathrm{~m}^{-2}(20 \%)$.

The application of the LLF + IM method, in the same way as already described for the sensible heat flux, worked well for the humidity measurements with the Helipod at $77 \mathrm{~m}$. The absolute mixing ratio measurement accuracy was set to $\sigma_{d}=0.15 \mathrm{~g} \mathrm{~kg}^{-1}$ (for both the Do 128 and the Helipod). The vertical gradient of the humidity flux differed slightly from the box method results due to the inaccurate scaling of the altitude axis. However, the extrapolated surface flux (Equation (6)) with an statistical uncertainty of $11.6 \%$, agreed well with the results from the box method and the ground measurements (including the lower two tower levels).

As Table II demonstrates there was no similarity in the inversely modelled parameters $m_{i}$ between the lowest Helipod (hbox 1 at $77 \mathrm{~m}$ ) and the lowest Do 128 (dbox1 at $200 \mathrm{~m}$ ) flight. On the other hand the parameters found during the flight dbox 0 performed about $30 \mathrm{~min}$ before agree well (within their uncertainties) with the dbox 1 data. For both flights the model 
quality test \#3 ( $\chi^{2}$ for data) succeeded only if the measurement uncertainty $\sigma_{d}$ was doubled to $0.3 \mathrm{~g}(\mathrm{~kg} \mathrm{~m})^{-1}$, which seemed to be unrealistic. The visual test \#4 showed that the forward-modelled time series did not follow the measurements. A very similar situation was found for the flights at $390 \mathrm{~m}$. When disregarding these quality-test failures the extrapolated surface fluxes had very large errors (Table II). The extrapolation of the two Do 128 flights at $200 \mathrm{~m}$ led even to negative surface humidity fluxes that totally disagreed with the surface observations.

These were examples of situations where a simple linear inverse model was not applicable, due to inappropriate model assumptions. Possibly a non-linear model would help but would require a much more complex numerical solution. The linear model was probably unsuitable for the given flow above $77 \mathrm{~m}$ due the increasing effect of convective moisture fluctuations with height. Close to the surface the convective elements were smaller than in the middle of the CBL. Measurements on a comparatively short flight leg of 10 or $15 \mathrm{~km}$ might mainly be dominated by short-lived convective elements rather than by the mean flow. A similar situation was found for the HELINEX campaign in 1997 (Wolff and Bange, 2000), which was characterised by vanishing mean horizontal gradients. This led to a failure of the LLF + IM, which was again indicated by the model quality tests \#3 and \#4. The calculated temporal and spatial gradients were mainly produced by short-lived convective elements and unsuitable for solving (5).

However, the quality control criteria indicated that the numerical inversion led to unreliable results in these cases. For real low-level flights as performed with the Helipod at $77 \mathrm{~m}$, the method worked fine.

\subsection{Application of LLF + IM to LITFASS-2003}

A larger field experiment was carried out in the same area around the observatory (MOL) between 19 May and 17 June 2003. LITFASS-2003 was organised within the framework of the EVA-GRIPS project and focused on the determination of the area-averaged evaporation over a heterogeneous land surface. The measurement program was developed based on the experiences from LITFASS-98 and included 14 micrometeorological surface stations, tower measurements at 50 and $90 \mathrm{~m} \mathrm{agl}$, the operation of three LAS (one of which was combined with a microwave scintillometer), and humidity flux profile measurements from a combination of a water vapour DIAL and a heterodyne wind lidar. Also, the flight component was more extensive than during LITFASS-98. The Helipod performed about $65 \mathrm{~h}$ of flight measurements mainly on square-shaped flight patterns that covered the entire investigation area. Several variations were flown, from simple squares to grid flights composed of several parallel legs. Their variations (e.g., big grid, wide grid, ... ) differed in the number of legs and the 


\section{J. BANGE ET AL.}

spacing between. Grid flights provide information about the inside of the experimental site, while box flights or simple squares only cover the edges. Due to a larger total flight distance, the grid flight strategy reduces on the one hand the statistical measurement errors, but on the other hand it consumes more time. The flights were performed at low levels, usually about $80 \mathrm{~m}$ above the ground. Additionally flights above homogeneous sub-areas (forest, lake, farmland) - so-called catalogue flights - were performed to obtain the individual surface fluxes of these surface types. Since the lake Scharmützelsee represented only $7 \%$ of the entire area the corresponding flight leg had to be excluded for the calculation of the area-averaged fluxes. Using the LLF + IM method the surface fluxes of sensible and latent heat were calculated.

From the eddy-covariance measurements at the 14 ground stations, flux composites were determined for each surface type. This was done by averaging the data from the individual stations operated over the same type of surface taking into account the data quality and the specific site characteristics of the individual measurements. A weighted average over the whole study region was calculated considering the relative occurrence frequency of the major land use types in the area. It was one aim of the Helipod flights to verify whether these flux composites from the ground measurements really provided area-averaged fluxes, representative for the entire site.

Figure 10 shows the direct comparison of airborne and ground-based sensible heat fluxes at ground level. The largest aberration from unity $(-0.33)$ was found for a flight with a large statistical error as well. The associated flight consisted of four legs (a simple square) only. Obviously this type of flight pattern provided less area-representative measurements compared to grid flights, causing a larger difference to the ground measurements. In general the ratio composite of Helipod measurements was between 0.78 and 1.17. Hence, the agreement between airborne and composite fluxes was quite satisfactory.

For the latent heat flux measurements (Figure 11) the scatter and also the statistical errors of the flight measurements were clearly larger. As shown before in the LITFASS-98 data the LLF + IM method has greater difficulties with the latent than with the sensible heat flux. Also the comparison with lidar measurements (Linné et al., 2006) demonstrated that the measurement of turbulent moisture fluxes is generally associated with larger statistical uncertainty, e.g. Flamant et al. (1997) found that large scales (larger than $4 \mathrm{~km}$ ) contribute to the latent heat flux while the sensible heat flux is more correlated with the convective structures. Thus the sensible heat flux is horizontally more homogeneous than the turbulent humidity flux. However, a systematic underestimation or overestimation of the heat fluxes, as reported from other field experiments (see Section 2), was not found. 
TURBULENT SURFACE FLUXES FROM LOW-LEVEL FLIGHTS USING INVERSE MODELS

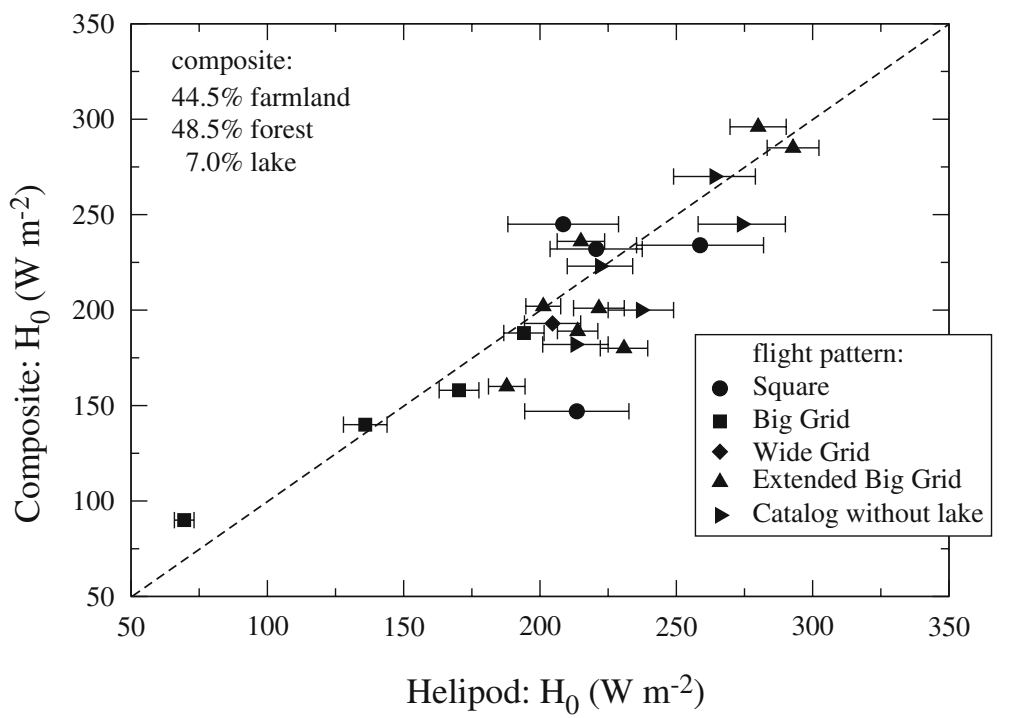

Figure 10. Scatter plot of the area-averaged sensible heat flux at surface level $H_{0}$ during the LITFASS-2003 experiment. Ordinate: composite ground measurements; abscissa: results from Helipod flights using the LLF + IM method. The symbols represent the various flight patterns, from simple squares consisting of four legs to close-meshed grids. The catalogue flights were added without the legs above the lake Scharmützelsee.

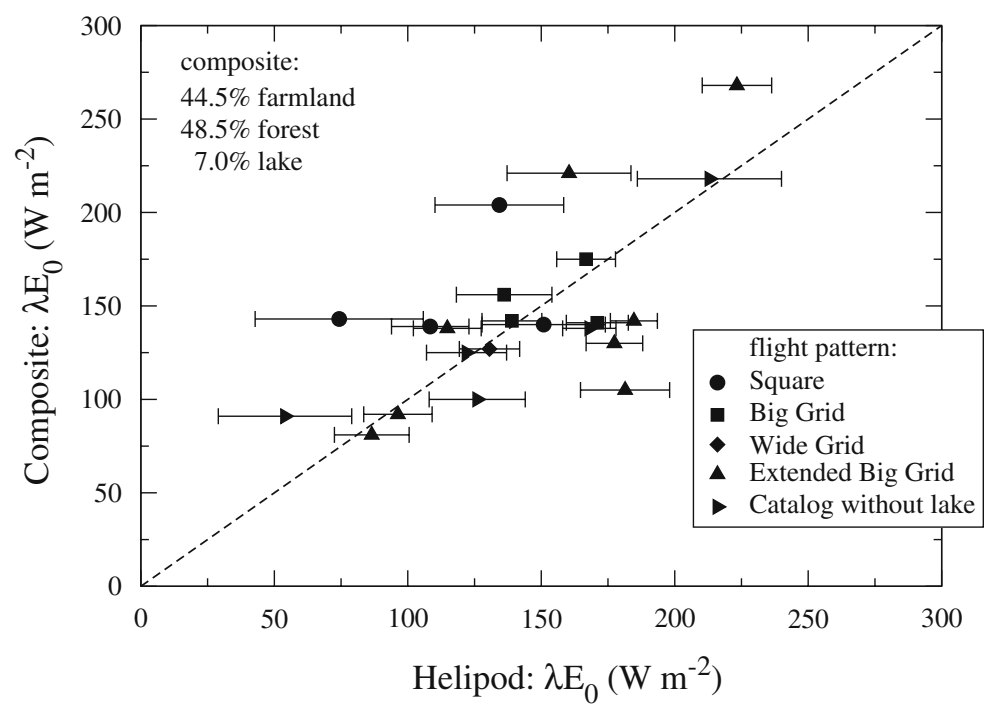

Figure 11. Scatter plot of the area-averaged latent heat flux at ground level $\lambda E_{0}$ during LITFASS-2003. For explanation, see Figure 10. 


\section{Summary and conclusions}

Research aircraft are very suitable for measuring area-representative turbulent fluxes in situ during a field experiment. The commonly applied box method, to measure the area-averaged fluxes at several altitudes and to extrapolate the results to the ground, can lead to a systematic error in the surface flux, as reported from other field experiments. With the exception of the sensible heat flux in a CBL a simple linear height profile of the flux cannot generally be assumed. Also flights at two or more levels are necessary, which is expensive and presupposes a stationary situation.

The low-level flight method as introduced by Grunwald et al. (1998) has big advantages compared to the box method. The vertical distance for the extrapolation can be reduced to the lowest $100 \mathrm{~m}$ agl or less, where assumptions about the vertical profile of the flux have to be made. A drawback of the LLF method again is the need for supporting measurements that provide the horizontal gradients of the mean atmospheric quantities in order to solve Equation (5) for the vertical flux divergence.

The combination of the LLF method with an inverse model solves this last problem. The horizontal gradients can be extracted from the airbornemeasured time series via a linear model assumption containing the spatial coordinates and the time. The advantage of inverse models (which require some numerical effort) against normal linear regressions is the extensive model quality control. The latter gives information about the success or failure of the numerical inversion.

Additionally, the calculated statistical error of the airborne flux measurements was reduced by the direct calculation of the integral length scale and the fourth-order statistical moments. Contrary to the recommended procedure (Lenschow and Stankov, 1986) no assumptions or estimations were applied. The error reductions achieved by this method were up to $50 \%$. The shorter statistical error bars were reliable, since during the LITFASS-98 flight experiment simultaneous airborne flux measurements at the same altitude but with different systems were almost identical.

The LLF + IM method was applied to simulated flight measurements in LES. In contrast to former investigations, small but systematic discrepancies between the 'true' vertical flux profiles and the 'airborne measurements' were found. Remarkably, these differences were height-dependent. Furthermore, their sign depended on whether the surface was homogeneous or heterogeneous. It was assumed that these discrepancies were connected to organised structures within the CBL that were especially vigorous due to the idealised numerical environment such as the tessellated surface. However, the vertical flux divergence calculated with the LLF + IM method at several flight levels was always identical to the LES 'truth'. 
The LLF + IM method was also tested in a real field experiment. Two airborne turbulence platforms, the Helipod and the Do 128, and several ground-based systems were employed in LITFASS-98, offering a good opportunity for an experimental validation of the method. The vertical sensible heat flux divergences derived from Do 128 and Helipod flights at 77 and $200 \mathrm{~m}$, respectively, agreed well and were consistent with the observations from a meteorological $99-\mathrm{m}$ tower. The extrapolation of these two flight levels led to almost identical surface fluxes $(10 \%$ difference) with $6.7 \%$ (Helipod at $77 \mathrm{~m}$ ) and $15.1 \%$ (Do 128 at $200 \mathrm{~m}$ ) statistical uncertainty. These findings agreed well with the averaged data from micrometeorological ground stations, LAS, and tower measurements. The overall results were clearly better and more reliable than the results obtained from the box method. At larger altitudes $(390 \mathrm{~m})$ the reliability of the LLF + IM method decreased with increasing statistical errors, although this is immaterial since the method was designed for low-level flights.

The determination of the area-averaged latent heat flux demonstrated the necessity of the inverse-model quality control. The inversion of the Helipod humidity measurements was performed uneventfully and led to surface fluxes in good agreement with the averaged ground measurements. After the numerical inversion of the Do 128 humidity measurements the model quality tests indicated a failure of the inversion. It was assumed that the failure was initiated by larger convective fluctuations of the moisture flux (compared to the sensible heat flux) in connection with short measurement runs. At $77 \mathrm{~m}$ the convective elements were supposed to be smaller, permitting the Helipod measurements to be modelled correctly by the applied linear inversion. A further analysis of this problem is necessary.

Flight measurements in conjunction with the LLF + IM method represent a powerful tool for determining area-averaged turbulent surface fluxes. In terms of long-running and more economical observations these airborne-derived surface fluxes can aid the search for averaging strategies for ground-based measurements. The method was applied to flights during the LITFASS-2003 field campaign, where larger statistical errors and non-systematic discrepancies (in both directions) were found for the Helipod and the ground measurements of the latent heat flux. On the other hand, the agreement of ground-based and airborne sensible heat flux measurements was encouraging and another proof of the LLF + IM method. Vice versa, assuming the airborne-derived surface fluxes were correct, the results demonstrate that the method of composite ground measurements provided reliable area-representative sensible heat fluxes. 


\section{Acknowledgements}

The ground, tower, and scintillometer data plotted in Figures 8 and 9 were collected by several groups participating in LITFASS-98. Thanks are due to Ulrich Weisensee (DWD), Wim Kohsiek (KNMI), Henk de Bruin (Wageningen University), Horst Lohse (GKSS), and Franz Berger (formerly at TU Dresden). The surface flux composites for LITFASS-2003 have been calculated by Jens-Peter Leps (DWD). This work was funded by the BMBF (German Federal Ministry for Education and Research), contract no. 07ATF37 (VERTIKO) and 01LD0301 (EVA-GRIPS).

\section{References}

Angevine, W. M., Avery, S. K., and Kok, G. L.: 1993, 'Virtual Heat Flux Measurements from a Boundary-Layer Profiler-RASS Compared to Aircraft Measurements', J. Appl. Meteorol. 32, 1901-1907.

Bange, J., Roth, R.: 1999, 'Helicopter-Borne Flux Measurements in the Nocturnal Boundary Layer Over Land - a Case Study', Boundary-Layer Meteorol. 92, 295-325.

Bange, J., Beyrich, F., and Engelbart, D. A. M.: 2002, 'Airborne Measurements of Turbulent Fluxes during LITFASS-98: A Case Study about Method and Significance', Theor. Appl. Climatol. 73, 35-51.

Berger, F.: 2002, 'Surface Radiant and Energy Flux Densities inferred from Satellite Data for the BALTEX Watershed'. Boreal. Env. Res. pp. 343-351.

Betts, A., Desjardins, R., MacPherson, J., and Kelly, R.: 1990, 'Boundary-Layer Heat and Moisture Budgets from FIFE', Boundary-Layer Meteorol. 50, 109-137.

Betts, A., Desjardins, R., MacPherson, J., and Kelly, R.: 1992, 'Budget Analysis of the Boundary Layer Grid Flights During FIFE 1987', J. Geophys. Res. 97, 18533-18546.

Beyrich, F., Berger, F., de Bruin, H., Foken, T., Kohsiek, W., Richter, S., and Weisensee, U.: 2002a, 'Experimental Determination of Turbulent Fluxes over the Heterogeneous LITFASS Area - Selected Results from the LITFASS-98 experiment', Theor. Appl. Climatol. 73, 19-34.

Beyrich, F., de Bruin, H. A. R., Meijninger, W. M. L., Schipper, J. W., and Lohse, H.: 2002b, 'Results from One-Year Continuous Operation of a Large Aperture Sintillometer over a Heterogeneous Land Surface', Boundary-Layer Meteorol. 105, 85-97.

Beyrich, F., Herzog, H.-J., and Neisser, J.: 2002c, 'The LITFASS Project of DWD and the LITFASS-98 Experiment: The Project Strategy and the Experimental Setup', Theor. Appl. Climatol. 73, 3-18.

Browne, L. W. B., Antonia, R. A., and Rajagopalan, S.: 1983, 'The Spatial Derivative of Tempeature in a Turbulent Flow and Taylor's Hypothesis', Phys. Fluids 26(5), 1222-1227.

Brümmer, B., and Thiemann, S.: 2002, 'The Atmospheric Boundary Layer in an Arctic Wintertime On-Ice Air Flow', Boundary-Layer Meteorol. 104, 53-72.

Burns, S. P., Khelif, D., Friehe, C. A., Williams, A. G., Hignett, P., Grant, A. L. M., Hacker, J. M., Rogers, D. P., Bradley, E. F., Weller, R. A., Cronin, M. F., Anderson, S. P., Fairall, C. W., and Paulson, C. A.: 1999, 'Comparison of Aircraft, Ship, and Buoy Meteorological Measurements from TOGA COARE', J. Geophys. Res. 104, 30853-30883.

Busch, U., Hofmann, M., Jacobi, C., and Roth, R.: 1996, 'Errors in Aircraft Measurements of Turbulent Fluxes in a Boundary Layer with Strong Convection', Phys. Chem. Earth 21, 393-397. 
TURBULENT SURFACE FLUXES FROM LOW-LEVEL FLIGHTS USING INVERSE MODELS

Chou, S.-H., Atlas, D., and Yeh, E.-N.: 1985, 'Turbulence in a Convective Marine Atomospheric Boundary Layer', J. Atmos. Sci. 43, 547-564.

Cleugh, H. A., Raupach, M. R., Briggs, P. R., and Coppin, P. A.: 2004, 'Regional-Scale Heat and Water Vapour Fluxes in an Agricultural Landscape: An Evaluation of CBL Budget Methods at OASIS', Boundary-Layer Meteorol. 110, 99-137.

Corsmeier, U., Hankers, R., and Wieser, A.: 2001, 'Airborne Turbulence Measurements in the Lower Troposphere Onboard the Research Aircraft Dornier 128-6, D-IBUF', Meteorol. Z., N. F. 4, 315-329.

de Arellano, J. V.-G., Gioli, B., Miglietta, F., Jonker, H. J. J., Baltink, H. K., Hutjes, R. W. A., and Holtslag, A. A. M.: 2004, 'Entrainment Process of Carbon Dioxide in the Atmospheric Boundary Layer', J. Geophys. Res. 109(D18110), doi:10.1029/2004JD004725.

Deardorff, J. W.: 1970, 'Convective Velocity and Temperature Scales for the Unstable Planetary Boundary Layer and for Rayleigh Convection', J. Atmos. Sci. 27, 1211-1213.

Deardorff, J. W.: 1974, 'Three-Dimensional Numerical Study of the Height and Mean Structure of a Heated Planetary Boundary Layer', Boundary-Layer Meteorol. 7, 81-106.

Deardorff, J. W.: 1980, 'Stratocumulus-Capped Mixed Layers derived from a Three-Dimensional Model', Boundary-Layer Meteorol. 18, 495-527.

Denmead, O. T., Raupach, M. R., Dunin, F. X., Cleugh, H. A., and Leuning, R.: 1996, 'Boundary Layer Budgets for Regional Estimates of Scalar Fluxes', Global Change Biol. 2, 255-264.

Desjardins, R. L., MacPherson, J. I., Schuepp, P. H., and Karanja, F.: 1989, 'An Evaluation of Aircraft Flux Measurements of $\mathrm{CO}_{2}$, Water Vapor and Sensible Heat', Boundary-Layer Meteorol. 47, 55-69.

Durand, P., Dupuis, H., Lambert, D., Bnech, B., Druilhet, A., Katsaros, K., Taylor, P., and Weill, A.: 1998, 'Comparison of Sea Surface Flux Measured by Instrumented Aircraft and Ship during SOFIA and SEMAPHORE Experiments', J. Geophys. Res. 103(C11), 25125-25136.

Engelbart, D. A. M., and Bange, J.: 2002, 'Determination of Boundary-Layer Parameters using Wind Profiler/RASS and Sodar/RASS in the Frame of the LITFASS-Project', Theor. Appl. Climatol. 73, 53-65.

Flamant, C., Pelon, J., Flamant, P. H., and Durand, P.: 1997, 'LIDAR Determination of the Entrainment Zone Thickness at the Top of the Unstable Marine Atmospheric Boundary Layer', Boundary-Layer Meteorol. 83, 247-284.

Grant, A.: 1986, 'Observations of Boundary Layer Structure Made during the 1981 KONTUR Experiment', Quart. J. Roy. Meteorol. Soc. 112, 825-841.

Grossman, R. L.: 1992a, 'Convective Boundary Layer Budgets of Moisture and Sensible Heat over an Unstressed Prairie', J. Geophys. Res. 97, 18425-18438.

Grossman, R. L.: 1992b, 'Sampling Errors in the Vertical Fluxes of Potential Temperature and Moisture Measured by Aircraft During FIFE', J. Geophys. Res. 97, 18439-18443.

Grunwald, J., Kalthoff, N., Corsmeier, U., and Fiedler, F.: 1996, 'Comparison of Areally Averaged Turbulent Fluxes over Non-Homogeneous Terrain: Results from the EFEDA-Field Experiment', Boundary-Layer Meteorol. 77, 105-134.

Grunwald, J., Kalthoff, N., Fiedler, F., and Corsmeier, U.: 1998, 'Application of Different Flight Strategies to Determine Areally Averaged Turbulent Fluxes', Contr. Atmos. Phys. 71, 283-302.

Gryning, S.-E., and Batchvarova, E.: 1999, 'Regional Heat Flux over the NOPEX Area Estimated from the Evolution of the Mixed Layer', Agric. For. Meteorol. 98-99, 159-167.

Haenel, H.-D., and Grünhage, L.: 1999, 'Footprint Analysis: A Closed Analytical Solution Based on Height-Dependent Profiles of Wind Speed And Eddy Viscoxity', BoundaryLayer Meteorol. 93, 395-409. 


\section{J. BANGE ET AL}

Hankers, R.: 1989, 'The Equipment of a Research Aircraft with Emphasis on Meteorological Experiments', in Soc. of Flight Test Eng., 20th Ann. Symp. Reno, Nevada, 7 pp.

Heinemann, G.: 2002, 'Aircraft-based Measurements of Turbulence Structures in the Katabatic Flow over Greenland', Boundary-Layer Meteorol. 103, 49-81.

Isaac, P. R., Mcaneney, J., Leuning, R., and Hacker, J. M.: 2004, 'Comparison of Aircraft and Ground-based Flux Measurements during OASIS95', Boundary-Layer Meteorol. 110, 39-67.

Jacobi, C., Scherf, A., Siemer, A. H., and Roth, R.: 1995, 'On the Influence of Sensor Ineria on the Estimation of Turbulent Fluxes from Aircraft Measurements', Boundary-Layer Meteorol. 76, 97-108.

Kelly, R. D., Smith, E. A., and MacPherson, J. I.: 1992, 'A Comparison of Surface Sensible and Latent Heat Fluxes from Aircraft and Surface Measurements in FIFE 1987', J. Geophys. Res. 97, 18445-18453.

Lambert, D., and Durand, P.: 1998, 'Aircraft to Aircraft Intercomparison during SEMAPHORE', JGR 103(C11), 25109-25123.

Lenschow, D. H., and Stankov, B. B.: 1986, 'Length Scales in the Convective Boundary Layer', J. Atmos. Sci. 43, 1198-1209.

Lenschow, D. H., Mann, J., and Kristensen, L.: 1994, 'How Long is Long Enough When Measuring Fluxes and Other Turbulence Statistics', J. Atmos. Oceanic Technol. 11, 661-673.

Linné, H., Hennemuth, B., Bösenberg, J., and Ertel, K.: 2006, 'Water Vapour Flux Profiles in the Convective Boundary Layer', Theor. Appl. Climatol., in press.

Lumley, L., and Panofsky, H.: 1964, The Structure of Atmospheric Turbulence, John Wiley \& Sons. 239 pp.

Mahrt, L., and Ek, M.: 1993, 'Spatial Variability of Turbulent Fluxes and Roughness Lengths in HAPEX-MOBILHY', Boundary-Layer Meteorol. 65, 381-400.

Mahrt, L., Vickers, D., Sun, J., and McCaughey, J. H.: 2001, 'Calculation of Area-Averaged Fluxes: Application to BOREAS', J. Appl. Meteorol. 40, 915-920.

Mann, J., and Lenschow, D. H.: 1994, 'Errors in Airborne Flux Measurements', J. Geophys. Res. D 99, 14519-14526.

Muschinski, A., and Wode, C.: 1998, 'First In-Situ Evidence for Co-Existing Sub-Meter Temperature and Humidity Sheets in the Lower Free Troposphere', J. Atmos. Sci. 55, 2893-2906.

Piacsek, S. A., and Williams, G. P.: 1970, 'Conservation Properties of Convection Difference Schemes', J. Comput. Phys. 6, 392-405.

Powell, D., and Eldekin, C.: 1974, 'An Investigation of the Application of Taylor's Hypothesis to Atmospheric Boundary Layer Turbulence', J. Atmos. Sci. 31, 990-1002.

Raasch, S., and Harbusch, G.: 2001, 'An Analysis of Secondary Circulations and their Effects Caused by Small-Scale Surface Inhomogeneities Using Large-Eddy Simulation', Boundary-Layer Meteorol. 101, 31-59.

Raasch, S., and Schröter, M.: 2001, 'PALM - A Large-Eddy Simulation Model Performing on Massively Parallel Computers', Meteorol. Z. 10, 363-372.

Roth, R., Hofmann, M., and Wode, C.: 1999, 'Geostrophic Wind, Gradient Wind, Thermal Wind, and the Vertical Windprofile - an Exemplary Analysis within a Planetary Boundary Layer over Arctic Sea-Ice', Boundary-Layer Meteorol. 92, 327-339.

Scherf, A., and Roth, R.: 1997, 'Estimates of Area-Averaged Turbulent Energy Fluxes in a Convectively Driven Boundary Layer Using Aircraft Measurements', Phys. Chem. Earth 21, 399-403.

Schröter, M., Bange, J., and Raasch, S.: 2000, 'Simulated Airborne Flux Measurements in a LES Generated Convective Boundary Layer', Boundary-Layer Meteorol. 95, 437-456. 


\section{TURBULENT SURFACE FLUXES FROM LOW-LEVEL FLIGHTS USING INVERSE MODELS}

Spieß, T., Zittel, P., and Bange, J.: 2004, 'The Role of the Helicopter-Borne Turbulence Probe Helipod in Joint Field Campaigns', in AMS: Eighth Symposium on Integrated Observing and Assimilation Systems for Atmosphere, Oceans, and Land Surface. Seattle, USA, P7.6, $6 \mathrm{pp}$.

Tarantola, A.: 1987, Inverse Problem Theory, Elsevier, Amsterdam, 613 pp.

Taylor, G.: 1938, 'The Spectrum of Turbulence', Proc. Roy. Soc. A 165, 476-484.

Wolff, M., and Bange, J.: 2000, 'Inverse Method as an Analysing Tool for Airborne Measurements', Meteorol. Z., N. F. 9, 361-376.

Zittel, P., Spieß, T., and Bange, J.: 2004, 'The Calculation of the Statistical Error of Measured Turbulent Fluxes - Considerations and Improvement', in AMS: 17th Conference on Probability and Statistics in the Atmospheric Sciences. Seattle, USA, 6.7, 5 pp. 